\title{
Nrf2 protects against diabetic dysfunction of endothelial progenitor cells via regulating cell senescence
}

\author{
RUI-YUN WANG ${ }^{1}$, LI-HUA LIU ${ }^{1}$, HONGXIA LIU ${ }^{1}$, KE-FEI WU ${ }^{1}$, JING AN $^{2}$, QIAN WANG ${ }^{1}$, \\ YUN LIU $^{1}$, LI-JUAN BAI ${ }^{1}$, BEN-MING QI ${ }^{3}$, BEN-LING QI $^{1}$ and LEI ZHANG ${ }^{2}$ \\ Departments of ${ }^{1}$ Geriatrics and ${ }^{2}$ Gastroenterology, Union Hospital, Tongji Medical College, \\ Huazhong University of Science and Technology, Wuhan, Hubei 430022; ${ }^{3}$ Department of Otorhinolaryngology, \\ First People's Hospital of Yunnan Province, Kunming, Yunnan 650000, P.R. China
}

Received February 19, 2018; Accepted June 8, 2018

DOI: $10.3892 /$ ijmm.2018.3727

\begin{abstract}
Diabetes is associated with an increased risk of cardiovascular disease. A decrease in the number and functionality of endothelial progenitor cells (EPCs) leads to reduced endothelial repair and the development of cardiovascular disease. The aim of the present study was to explore the effect and underlying mechanisms of nuclear factor erythroid 2-related factor 2 (Nrf2) on EPC dysfunction caused by diabetic mellitus. The biological functions of EPCs in streptozotocin-induced diabetic mice were evaluated, including migration, proliferation, angiogenesis and the secretion of vascular endothelial growth factor (VEGF), stromal-derived growth factor (SDF) and nitric oxide (NO). Oxidative stress levels in diabetic EPCs were also assessed by detecting intracellular reactive oxygen species (ROS), superoxide dismutase (SOD) and malondialdehyde (MDA). EPC senescence was evaluated by measuring p16 and b-gal expression and observing the senescence-associated secretory phenotype. In addition, the function of EPCs and level of oxidative stress were assessed following Nrf2 silencing or activation. Nrf2 silencing resulted in a decrease of EPC biological functions, accelerated cell senescence and increased oxidative
\end{abstract}

Correspondence to: Dr Ben-Ling Qi, Department of Geriatrics, Union Hospital, Tongji Medical College, Huazhong University of Science and Technology, 1277 Jiefang Avenue, Wuhan, Hubei 430022, P.R.China

E-mail: qibenlingok_2015@163.com

Abbreviations: EPCs, endothelial progenitor cells; DM, diabetes mellitus; STZ, streptozotocin; SDF-1, stromal-derived factor-1; NO, nitric oxide; SOD, superoxide dismutase; Dil-acLDL, 1,1'-dioctadecyl-3,3,3',3'-tetramethylindo-carbocyanine-labeled acetylated low density lipoprotein; VEGFR2, vascular endothelial growth factor receptor 2; tBHQ, tert-Butylhydroquinone; KEAP1, kelch-like ECH-associated protein-1; HO-1, heme oxygenase-1; Nrf2, nuclear factor erythroid 2-related factor 2; NQO-1, quinone oxidoreductase-1; SASP, senescence-associated secretory phenotype

Key words: endothelial progenitor cells, diabetic mellitus, oxidative stress, nuclear factor erythroid 2-related factor 2, senescence stress, as indicated by ROS and MDA upregulation accompanied with decreased SOD activity. Furthermore, Nrf2 silencing inhibited migration, proliferation and secretion in EPCs, while it increased oxidative stress and cell senescence. Nrf2 activation protected diabetic EPCs against the effects of oxidative stress and cell senescence, ameliorating the biological dysfunction of EPCs derived from mice with diabetes. In conclusion, Nrf2 overexpression protected against oxidative stress-induced functional damage in EPCs derived from diabetic mice by regulating cell senescence.

\section{Introduction}

Cardiovascular disease (CVD) causes high mortality worldwide (1). Diabetes mellitus (DM) is a common, chronic, metabolic disease that causes a great socioeconomic burden, and the incidence of DM is increasing. Compared with non-diabetic individuals, patients with DM have an increased risk of CVD (2). DM is often accompanied by vascular complications, including vascular remodeling and vascular growth disorders, decreased response to hypoxia-ischemia sites, abnormal neovascularization, and impaired endothelium regeneration (3). Therefore, therapeutic interventions that ameliorate endothelial dysfunction may be a promising strategy for DM.

Endothelial progenitor cell (EPC) dysregulation has been reported in the pathogenesis of diabetic vasculopathy (4). A number of studies have suggested that bone-marrow derived EPCs contribute to postnatal neovascularization and vascular endothelial repair $(5,6)$. When vascular injury occurs, EPCs are mobilized from the bone marrow, enter the circulation and translocate to sites of endothelial damage to induce neovascularization and repair vascular damage (7). In the past decade, endothelial progenitor cell (EPC) transplantation has been used experimentally to treat CVD (8). Several studies have reported that EPC transplantation is beneficial in CVD, and transplanted EPCs may compensate for the insufficiency of endogenous EPCs in diabetic retinopathy (9). However, in order to improve therapeutic efficacy of EPC transplantation, it is necessary to improve EPC survival and proliferation.

The transcription factor, nuclear factor erythroid 2-related factor $2(\mathrm{Nrf} 2)$, is a receptor for exogenous toxic substance 
oxidative stress. Nrf2 serves an important role in the major defense mechanisms associated with cellular antioxidative stress and the induction of exogenous toxic substances $(10,11)$. Under normal conditions, Nrf2 exists in a complex with Kelch-like ECH-associating protein 1 (Keap1), its repressor protein, and is tethered to the actin cytoskeleton in the cytosol. The interaction between Nrf2 and Keap1 causes its continual ubiquitination and degradation $(12,13)$. Under oxidative stress, activated Nrf2 translocates and accumulates in the nucleus, binding to the promoters of genes that contain the antioxidant response element, inducing transcription (14-16). Nrf2 and its target genes serve roles in the antioxidant response, detoxification, glutathione homeostasis and other cytoprotective functions (17-19). Previous studies have reported that Nrf2 is inducible and upregulates Heme oxygenase-1 (HO-1), as well as NADPH quinone oxidoreductase 1 (NQO1) in leukocytes $(20,21)$. Therefore, Nrf2 activity can be assessed by measuring the induction of NQO1 and HO-1 mRNA expression. Tert-butylhydroquinone (tBHQ), one of the most studied Nrf2 inductors, is present in the human body and is used as a food preservative widely. Nrf2 may be the key factor in cell homeostasis. It has been reported that CXC chemokine ligand 7 (CXCL7) upregulation improves the angiogenesis of EPCs via Nrf2 activation in diabetic ischemia (22), and that hyperglycemia induces EPC senescence (23). However, whether Nrf2 serves a direct role in regulating the functions and senescence in DM remains unclear.

The aim of the present study was to investigate the potential role of Nrf2 in the biological functions of EPCs in DM, including migration, proliferation, secretion and angiogenesis, as well as its relevance in oxidative stress and cell senescence.

\section{Materials and methods}

Animals and diabetic models. Male C57BL/6 male mice weighing 18-20 g (7-8 weeks) were purchased from the Beijing Vital River Laboratory Animal Technology Co. Ltd. (Beijing, China). The animals were housed in cages at $22 \pm 2^{\circ} \mathrm{C}$ with $40 \pm 5 \%$ humidity under a 12 -h light/dark cycle, and received standard diet and water ad libitum. Mice were handled according to the institutional animal care guidelines and the Guide for Care and Use of Laboratory Animals published by Tongji Medical College (Huazhong University of Science and Technology, Wuhan, China). Mice were randomly divided into two groups: the control group and the diabetic group $(n=40)$. Mice in the diabetic group were intraperitoneally administered with streptozotocin (STZ; $60 \mathrm{mg} / \mathrm{kg} /$ day for 5 days) dissolved in $0.1 \mathrm{mM}$ sodium citrate buffer, while mice in the control group were administered with isometric $0.1 \mathrm{mM}$ sodium citrate buffer ( $\mathrm{pH} 4.5$ ). Blood glucose levels and body weight were measured every 2 weeks for the following 8 weeks, and blood glucose concentrations $\geq 16.7 \mathrm{mmol} / \mathrm{l}$ (300 mg/dl) was considered modeling success. All experiments were approved by the Ethics Committee of Tongji Medical College, Huazhong University of Science and Technology.

Isolation and culture of EPCs. EPCs were isolated and cultured as previously described (24). In brief, bone marrow mononuclear cells were extracted from the tibia and femurs of mice and cultured on fibronectin-coated 6-well plates in endothelial cell basal medium-2 (Lonza Group, Ltd., Basel, Switzerland) supplemented with endothelial cell growth medium-2 (EGM-2) SingleQuot kit supplement (Lonza Group, Ltd.). Following 4 days of culture, nonadherent cells were removed by washing the plates with PBS. The remaining cells were cultured for another 3 days (total 7 days) and used for further analysis (25). The cultured EPCs from each mouse were used for 1-2 cell function experiments.

Characterization of EPCs. According to previous publications (5,25-28), adherent EPCs were positive for CD45, the endothelial and hematopoietic cell marker (29), and were subjected to dual staining for acetylated low-density lipoprotein (acLDL; Thermo Fisher Scientific, Inc., Waltham, MA, USA) and 1 fluorescein isothiocyanate (FITC)-conjugated BS-1 lectin, followed by flow cytometry analysis. Flow cytometry was also used to assess the expression of cell surface antigens with the following antibodies (eBioscience; Thermo Fisher Scientific, Inc.): FITC-conjugated anti-mouse CD34 antibody; allophycocyanin (APC)-conjugated anti-mouse CD133 (also known as Prominin-1) antibody; phycoerythrin (PE)-conjugated anti-mouse CD309 (also known as FLK1/VEGF-R2/KDR) antibody and PerCP-Cyanine5.5-conjugated anti-mouse CD45 antibody. More than 6 mice were included in this experiment.

\section{EPC migration evaluation (Transwell and wound healing} assays). EPC migration was evaluated using a modified Boyden's chamber assay as previously described (30). Briefly, cell suspensions $\left(5 \times 10^{4}\right.$ cells/well $)$ were seeded in the upper chamber, and EGM-2 medium containing human recombinant vascular endothelial growth factor (VEGF; $50 \mathrm{ng} / \mathrm{ml}$; R\&D Systems Inc., Minneapolis, MN, USA) was used to fill the lower chamber. The chamber was incubated for $24 \mathrm{~h}$ under $5 \%$ $\mathrm{CO}_{2}$ at $37^{\circ} \mathrm{C}$, then washed with PBS, fixed with $4 \%$ paraformaldehyde and stained with crystal violet. Migration activity was evaluated by counting the mean number of migrated cells under a microscope (Olympus Corp., Tokyo, Japan) in three random high-power fields. Cell migration was also assessed using an in vitro scratch wound healing assay as previously described (31). EPCs were cultured in 6-well plates with EGM-2 medium supplemented with $10 \%$ fetal bovine serum (Thermo Fisher Scientific, Inc.) until they reached $100 \%$ confluence. A sterile $200 \mu \mathrm{l}$ pipette tip was used to make a straight scratch in the surface. Cells were washed three times with PBS and cultured with serum free EGM-2 medium for $24 \mathrm{~h}$. The shortest vertical distance of the scratch was observed using an inverted microscope (magnification, x100) to determine cell migration at 0, 6, 12 and $24 \mathrm{~h}$. More than 6 mice were included in each group.

EPC proliferation evaluation [5-ethynyl-2'-deoxyuridine (EdU) incorporation assay]. An EdU labeling/detection kit (Guangzhou Ribobio Co., Ltd., Guangzhou, China) was used to evaluate the proliferation of EPCs, according to the manufacturer's protocol. Briefly, EPCs were cultured in 24-well plates at a density of $5 \times 10^{4}$ cells/well. Following exposure to the indicated experimental conditions, EPCs were labeled with $50 \mu \mathrm{M}$ EdU labeling media and incubated for $4 \mathrm{~h}$ at $37^{\circ} \mathrm{C}$ under $5 \% \mathrm{CO}_{2}$, then fixed with $4 \%$ paraformaldehyde, lysed using $0.5 \%$ Triton $\mathrm{X}-100$, and stained with anti-EdU working 
A

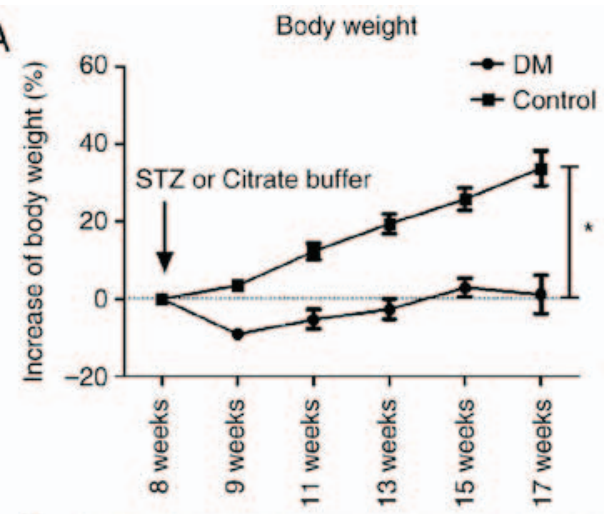

C

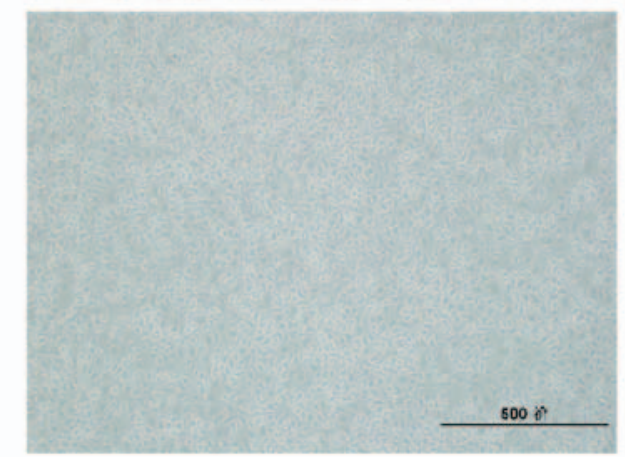

$\mathrm{D}$
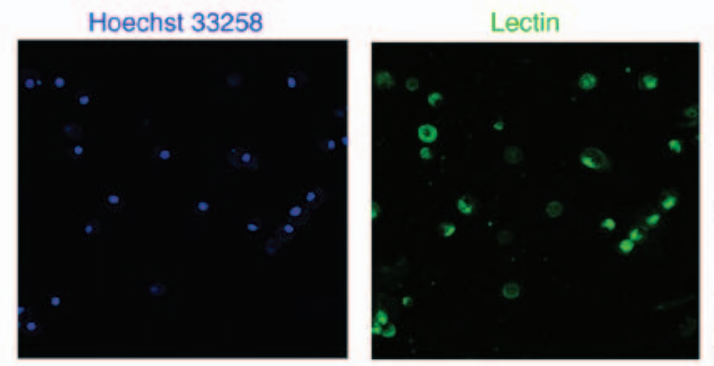

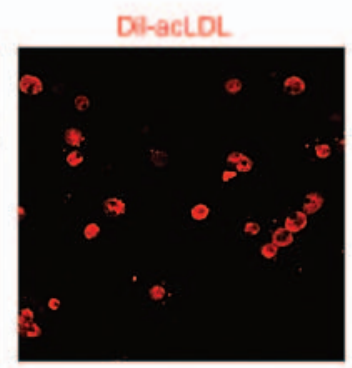

B
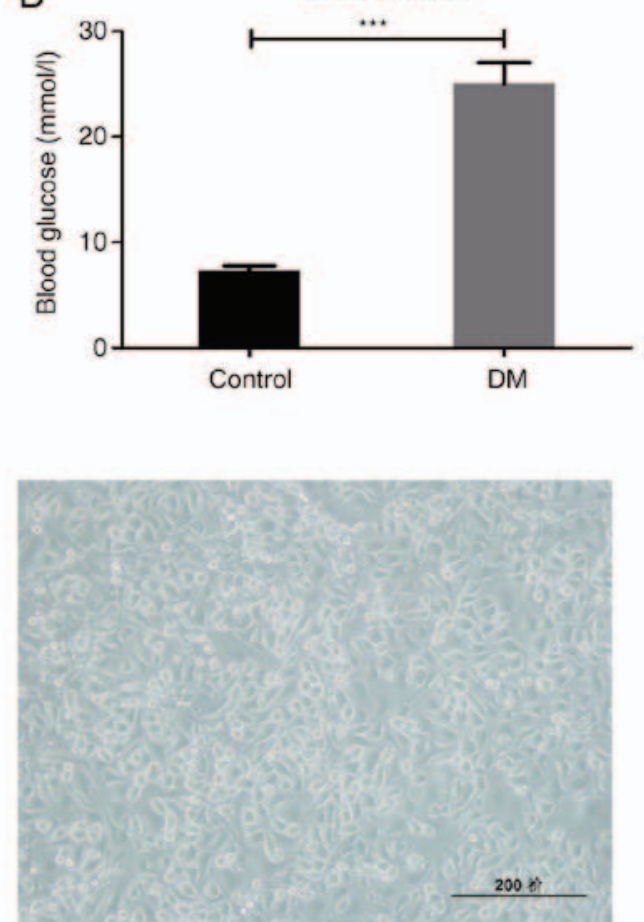

E
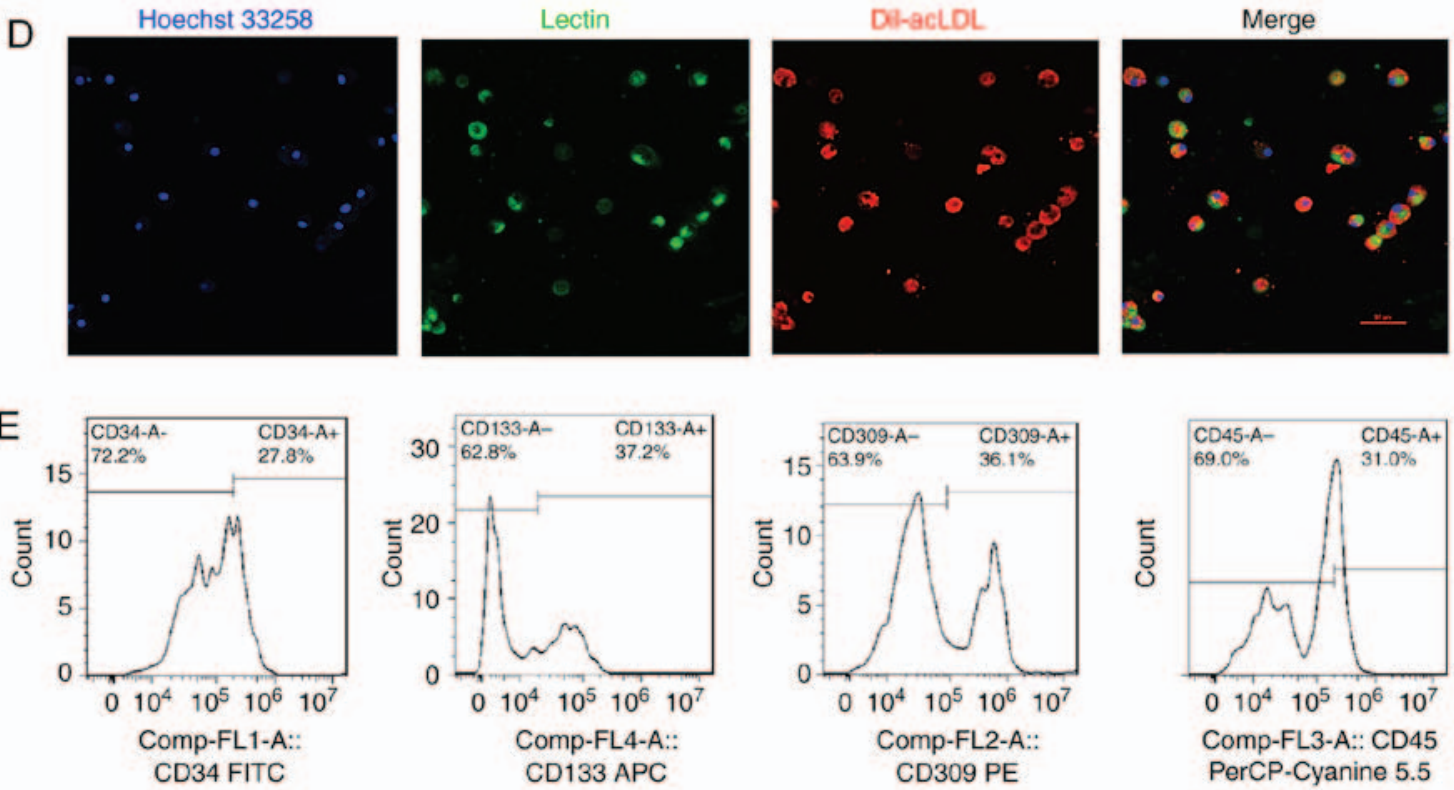

Figure 1. Characterization of early EPCs derived from the STZ-induced DM mice. (A) Blood glucose and (B) body weight measurements in STZ-induced DM mice. (C) The isolated mononuclear cells became spindle-shaped following 7 days of culture. Scale bar, 500 (left) and 200 (right) $\mu \mathrm{m}$. (D) The EPCs were identified as double positive for Dil-acLDL (red) and lectin (green) following 7 days of culture. Scale bar, $50 \mu \mathrm{m}$. (E) Early EPCs were further confirmed by expression of well-established cell surface markers CD34, CD133, VEGFR2 and CD45 ${ }^{\text {dim }}$. $\mathrm{P}<0.05$ and ${ }^{* * *} \mathrm{P}<0.001$ compared with control ( $\mathrm{n}=10$ ). EPCs, endothelial progenitor cells; STZ, streptozotocin; DM, diabetes mellitus; Dil-acLDL, 1,1'-dioctadecyl-3,3,3',3'-tetramethylindo-carbocyanine-labeled acetylated low density lipoprotein; VEGFR2, vascular endothelial growth factor receptor 2; FITC, fluorescein isothiocyanate.

solution. The nuclei were labeled with Hoechst 33258 (Guge, Wuhan, China), and the percentage of EdU-positive EPCs was calculated following fluorescent microscopy (Olympus Corp.). Five random fields of view were assessed for each group. More than 4 mice were included in each group.

Tube formation assay. Matrigel matrix (BD Biosciences, Franklin Lakes, NJ, USA) was placed in the well of a 48-well cell culture plate, after which $2 \times 10^{3}$ Dil-labeled EPCs and
$2 \times 10^{4}$ human umbilical vein endothelial cells (HUVECs, ATCC ${ }^{\circledR}$ CRL-1730 ${ }^{\text {TM }}$ ) which were purchased from the American Type Culture Collection (Manassas, VA, USA), were added in each well with EGM-2. After $18 \mathrm{~h}$ of incubation, images of tube morphology were captured. More than 4 mice were included in each group.

Measurement of VEGF, stromal-derived growth factor(SDF) and nitric oxide (NO) secretion. To measure the secretion functions 


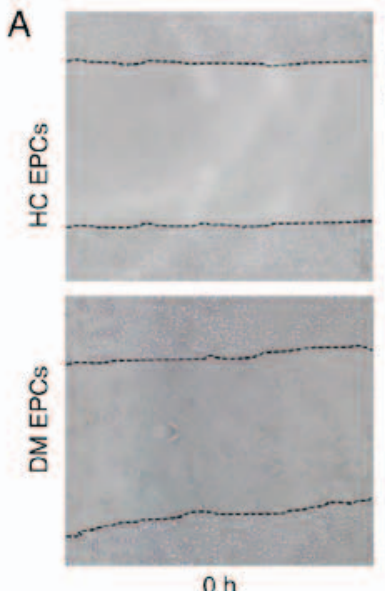

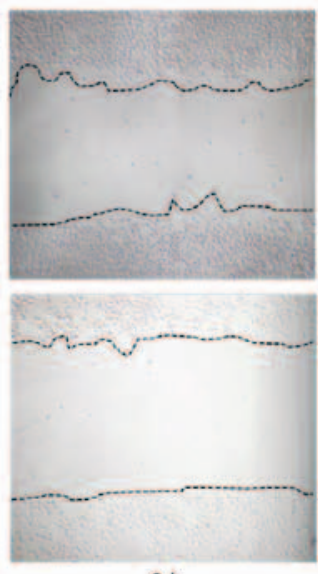

$6 \mathrm{~h}$
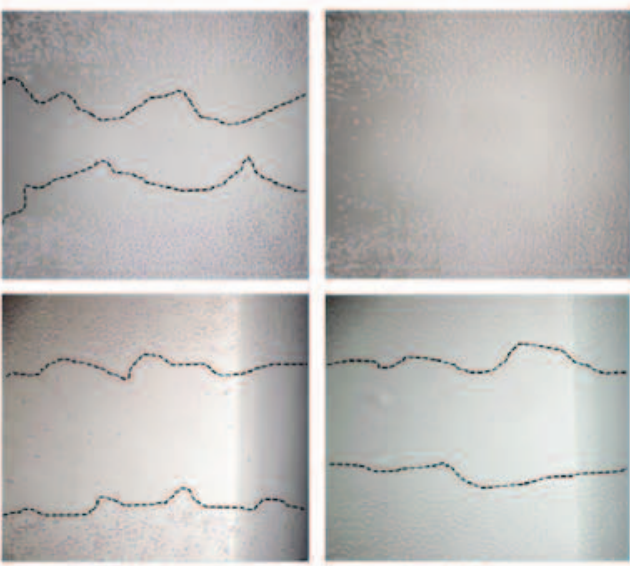

$12 \mathrm{~h}$

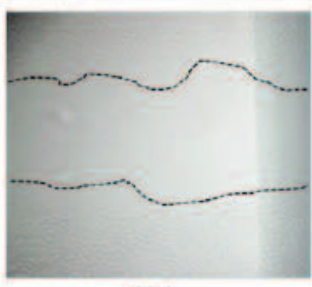

$24 \mathrm{~h}$

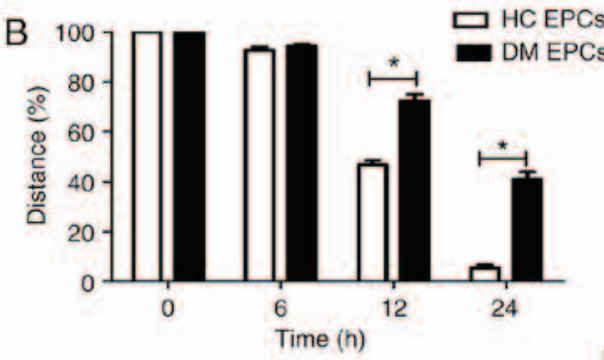

$\left.D{ }^{60}\right] \longmapsto$ •

$\mathrm{E}$

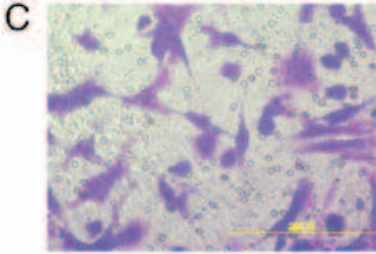

HC EPCs

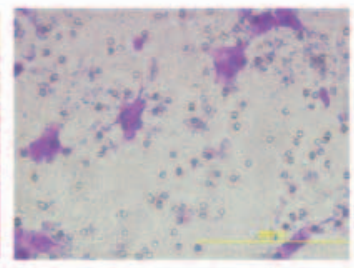

DM EPCs

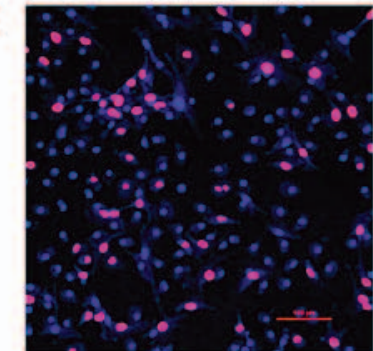

HC EPCs

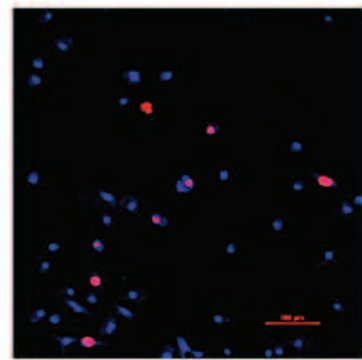

DM EPCs

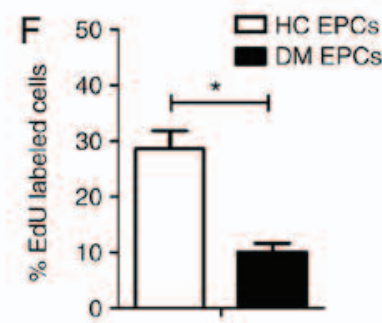

G

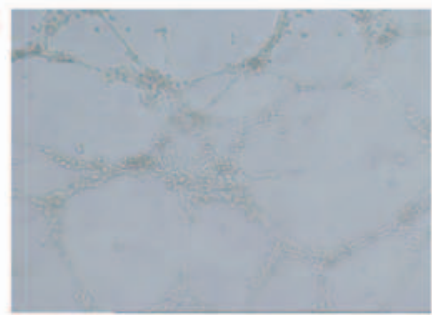

HCEPCS
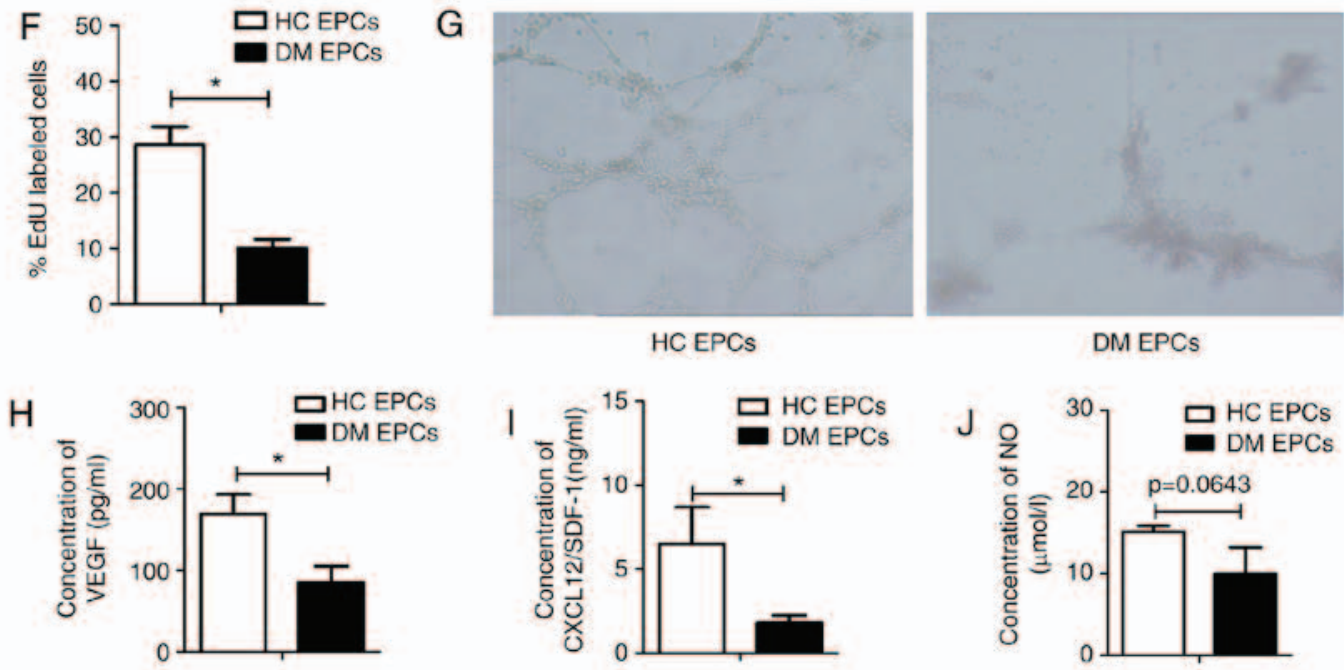

DM EPCS

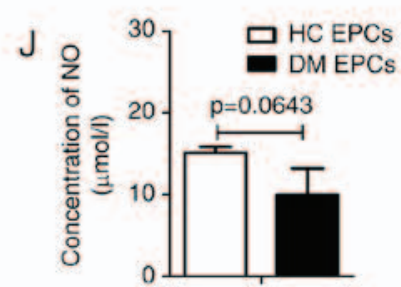

Figure 2. Impaired migration, proliferation, secretion and angiogenesis of EPCs in DM mice. (A) Representative images and (B) quantification of wound healing assays with EPCs isolated from DM mice and control mice at time 0, 6, 12 and 24 h. Magnification, x100. The black dotted line shows the edge of the cells. (C) Representative images and (D) quantification of crystal violet-stained migrated cells, as assessed by Transwell assay. Magnification, $\mathrm{x} 400$. (E) Representative images and (F) quantification of EdU staining (red), to measure the proliferative ability of EPCs. Scale bar, $100 \mu \mathrm{m}$. (G) Representative images showing tube-forming activity. Magnification, x100. (H) Levels of secreted VEGF, (I) SDF-1 and (J) NO in the supernatant of cultured EPCs. "P<0.05 compared with control ( $\mathrm{n}=4-8)$. EPCs, endothelial progenitor cells; DM, diabetes mellitus; VEGF, vascular endothelial growth factor; SDF-1, stromal-derived factor-1; NO, nitric oxide; $\mathrm{HC}$, healthy control.

of EPCs, SDF-1 and VEGF levels in the cell culture supernatants were determined using ELISA kits (anti-mouse VEGF ELISA kit, cat. no. EMC103, Neo Bioscience Technology, China; CXCL12/SDF-1 $\alpha$ Quantikine ELISA kit, cat. no. MCX120, 
A

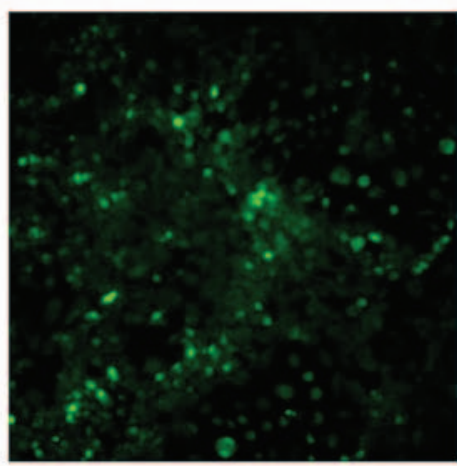

HC EPCs

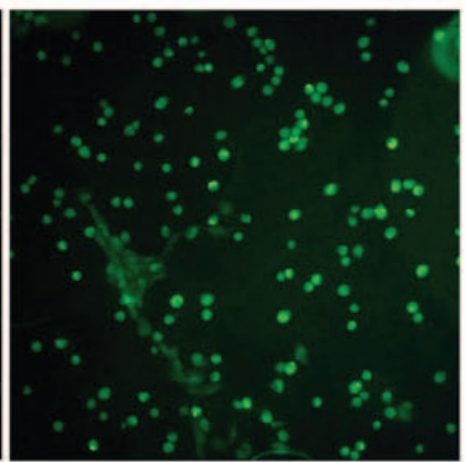

B

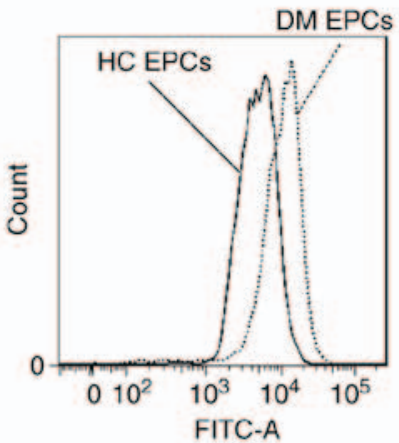

C

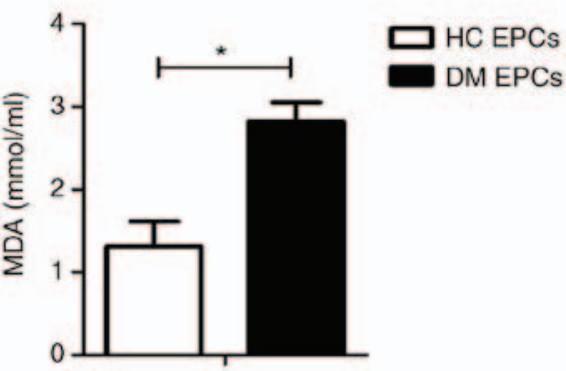

E

NRF2

Control

DM

$\beta$-actin

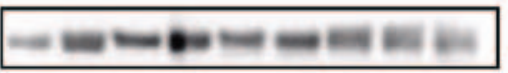

DM EPCs

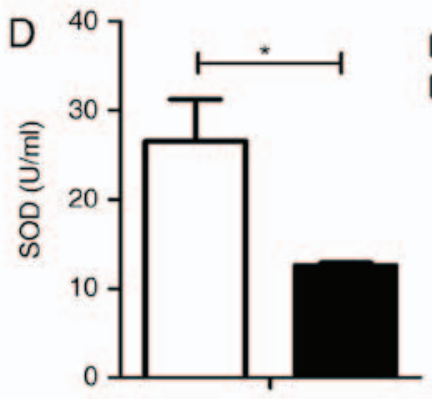

HC EPCs

DM EPCs
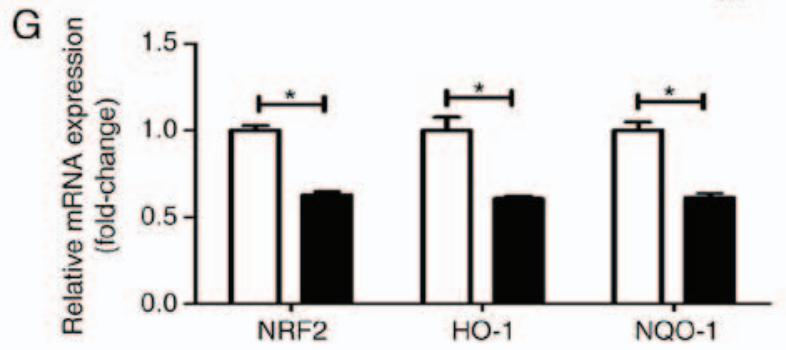

F

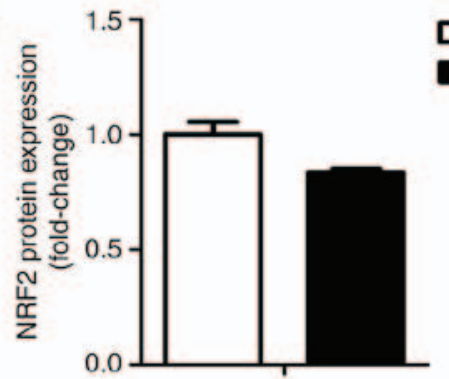

Figure 3. Decreased Nrf2 expression and increased oxidative stress levels in diabetic EPCs. (A) ROS levels in EPCs were detected utilizing CellROX Green reagent. Representative fluorescent images are shown. Magnification, x100. (B) ROS levels in EPCs as measured by flow cytometry. (C) MDA levels were increased and (D) SOD activity was decreased in the supernatant of diabetic EPCs. (E) Representative blots and (F) quantification of Nrf2 protein expression levels in control and diabetic EPCs. (G) mRNA expression levels of Nrf2, HO-1 and NQO-1 were decreased in diabetic EPCs. "P<0.05 compared with control $(\mathrm{n}=8)$. Nrf2, nuclear factor erythroid 2-related factor 2; EPCs, endothelial progenitor cells; DM, diabetes mellitus; ROS, reactive oxygen species; MDA, malondialdehyde; SOD, superoxide dismutase; HO-1, heme oxygenase-1; NQO-1, quinone oxidoreductase-1; HC, healthy control.

R\&D Systems, Inc.), according to the manufacturer's protocols. NO released from EPCs was assessed by measuring the stable breakdown product of $\mathrm{NO}$ in the culture supernatant with a commercial NO colorimetric assay kit (Enzo Life Sciences, Inc., Farmingdale, NY, USA) according to the manufacturer's protocol. More than 6 mice were included in each group.

Measurement of intracellular reactive oxygen species (ROS). Intracellular ROS levels were determined using imaging and flow cytometry analysis. Following exposure to the indicated experimental conditions, EPCs were stained with $5 \mu \mathrm{mol} / \mathrm{l}$
CellROX Green reagent (Thermo Fisher Scientific, Inc.) and incubated for $40 \mathrm{~min}$ at $37^{\circ} \mathrm{C}$, following which the medium was removed and cells were washed three times with PBS. Cells were fixed with $4 \%$ formaldehyde for $15 \mathrm{~min}$, after which the nuclei were stained with Hoechst 33258 and examined using a fluorescent microscope (Olympus Corp.). For flow cytometry analysis, EPCs were incubated with CellROX Green reagent, washed 3 times with PBS, trypsinized and detected using a flow cytometer (FACSCalibur; BD Biosciences). Data were analyzed using FlowJo software (FlowJo LLC, Ashland, OR, USA). More than 6 mice were included in each group. 
Superoxide dismutase (SOD) and malondialdehyde (MDA) assay. SOD activity and MDA content in the media were measured using commercially available kits and colorimetric assays (Nanjing Jiancheng Bioengineering Institute, Nanjing, China) according to the manufacturer's protocols (31). More than 6 mice were included in each group.

Small-interfering RNA (siRNA) transfection. Nrf2 expression was silenced using siRNA (siRNA mouse Silencer select Nrf2, gene ID: 18024; Guangzhou RiboBio Co., Ltd.), according to the manufacturer's protocol with a riboFECT CP Transfection kit (Guangzhou RiboBio Co., Ltd.) after determining optimal transfection conditions (data not shown). The siRNA sequence (sense strand) used for targeting Nrf2 was CGACAGAAACCTCCATCTA. A Stealth RNAi Negative Control Duplex (Guangzhou RiboBio Co., Ltd.) was used as a negative control. To measure biological function, and to examine protein and mRNA levels, EPCs were collected at 48 and $72 \mathrm{~h}$ post-transfection, respectively. More than 6 mice were included in each group.

Western blotting. Western blotting for Nrf2 was performed in EPCs in each group. Total proteins were prepared with RIPA lysis buffer at $4^{\circ} \mathrm{C}$ for $0.5 \mathrm{~h}$ (Beyotime Institute of Biotechnology, Haimen, China) and quantified using a BCA kit (Beyotime Institute of Biotechnology). Aliquots of cell lysates $(50 \mu \mathrm{g})$ were separated by $10 \%$ SDS-PAGE, electrotransferred to a polyvinylidene difluoride (PVDF) membrane (Bio-Rad Laboratories, Inc.) and blocked with TBS/0.1\% Tween-20 (TBS-T) buffer with $5 \%$ nonfat milk for $1 \mathrm{~h}$ at room temperature. Membranes were incubated with the appropriate primary antibody (anti-Nrf2, 1:1,000; cat. no. 12721 or anti- $\beta$-actin, 1:2,000, cat. no. 4970; Cell Signaling Technology, Inc., Danvers, MA, USA; anti-p16, 1:1,000, cat. no. ARG57377, Arigo Biolaboratories Corp., Taiwan, ROC) at $4^{\circ} \mathrm{C}$ overnight. The PVDF membranes were washed with TBS-T buffer followed by incubation with horseradish peroxidase (HRP)-conjugated secondary antibody anti rabbit immunoglobulin G (H+L; cat. no. ANT020; Antgene Biotechnology Co., Ltd., Wuhan, China) at room temperature for $1 \mathrm{~h}$. Following extensive washing, the bands were detected using a Chemiluminescence Detection System (ECL; Thermo Fisher Scientific, Inc.). More than 4 mice were included in each group.

Reverse transcription-quantitative polymerase chain reaction $(R T-q P C R)$. Total RNA of cultured EPCs was isolated with TRIzol Reagent according to the manufacturer's protocol (Thermo Fisher Scientific, Inc.). Complementary DNA was synthesized using the PrimeScript RT Master Mix kit (Takara Biotechnology Co., Ltd., Dalian, China) and then used for qPCR with a QuantiTect SYBR-Green PCR kit (Qiagen $\mathrm{GmbH}$, Hilden, Germany) on a ROCHE LightCycler ${ }^{\circledR} 480$ System (Roche Diagnostics GmbH, Basel, Switzerland). The primer sequences were as follows: $\beta$-actin forward, 5 '-GGC TGTATTCCCCTCCATCG-3' and reverse, 5'-CCAGTTGGT AACAATGCCATGT-3'; Nrf2 forward, 5'-TCCATTTCC GAGTCACTGAACCCA-3' and reverse, 5'-TGACTCTGAC TCCGGCATTTCACT-3'; HO-1 forward, 5'-AGGTACACA TCCAAGCCGAGA-3' and reverse, 5'-CATCACCAGCTT AAAGCCTTCT-3'; NQO-1 forward, 5'-AGGATGGGAGGT
ACTCGAATC-3' and reverse, 5'-TGCTAGAGATGACTC GGAAGG-3'; p16 forward, 5'-CGCAGGTTCTTGGTCACT GT-3' and reverse, 5'-TGTTCACGAAAGCCAGAGCG-3'; interleukin 6 (IL-6) forward, 5'-TAGTCCTTCCTACCC CAATTTCC-3' and reverse, 5'-TTGGTCCTTAGCCACTCC TTC-3'; monocyte chemotactic protein-2 (MCP-2) forward, 5'-TCTACGCAGTGCTTCTTTGCC-3' and reverse, 5'-AAG GGGGATCTTCAGCTTTAGTA-3'; tumor necrosis factor $\alpha$ (TNF- $\alpha$ ) forward, 5'-CCCTCACACTCAGATCATCTTCT-3' and reverse, 5'-GCTACGACGTGGGCTACAG-3'; vascular cell adhesion molecule 1 (VCAM-1) forward, 5'-AGTTGG GGATTCGGTTGTTCT-3' and reverse, 5'-CCCCTCATTCCT TACCACCC-3'. The thermocycling conditions were as follows: $95^{\circ} \mathrm{C}$ for $10 \mathrm{~min}$, and 45 cycles of $95^{\circ} \mathrm{C}$ for $15 \mathrm{sec}$ and $60^{\circ} \mathrm{C}$ for $15 \mathrm{sec}$. The relative expression was analyzed according to the $2^{-\Delta \Delta \mathrm{Cq}}$ method (32). qPCR was performed with 2 replicates of each sample, and more than 6 mice were included in each group.

Senescence-associated- $\beta$-galactosidase (SA- $\beta$-gal) staining. EPCs were stained using a Senescence Cells Histochemical Staining kit (Beyotime Institute of Biotechnology), according to the manufacturer's protocols, to assess senescence. Senescence was quantitated by visual inspection of blue/green stained cells with an inverted microscope (magnification, x10). More than 4 mice were included in each group.

Statistical analysis. Data are expressed as the mean \pm standard error of mean. Differences between groups were evaluated using either two-tailed Student's t-test or one-way analysis of variance followed by Dunnett's T3 post hoc test. All statistical analyses were performed using the SPSS software version 19.0 (IBM SPSS, Armonk, NY, USA). $\mathrm{P}<0.05$ was considered to indicate a statistically significant difference.

\section{Results}

Characteristics of early EPCs. In the STZ-induced DM mice, body weight gain was significantly slowed (Fig. 1A), while blood glucose levels were significantly increased (Fig. 1B), compared with the control mice. Following isolation and 7-day culture in EGM-2 medium, mononuclear cells became spindle shaped (Fig. 1C), and double positive for acetylated low-density lipoprotein-lectin (Dil-acLDL) uptake and lectin binding affinity (Fig. 1D), which are hallmarks of EPCs. In addition, flow cytometry analysis revealed that the expression of CD34 (27.8 \%), CD133 (37.2\%), VEGF receptor 2 (36.1\%) and $\mathrm{CD} 45^{\mathrm{dim}}(69.0 \%)$, the most widely used EPC markers in the literature $(5,22,24-28)$, further confirmed the characteristics of early EPCs (Fig. 1E), consistent with previous reports $(5,22,28)$. Therefore, the cells isolated and cultured in the present study were considered suitable to further examine the properties of EPCs.

The biological functions of EPCs are impaired in DM mice. Wound healing and Transwell assays were used to examine the migratory capacity of EPCs isolated from mice in the DM and control groups. Scratch wound healing assay results indicated that the migration of EPCs was significantly decreased in DM mice compared with the control group at 12 and $24 \mathrm{~h}(\mathrm{P}<0.05$; 

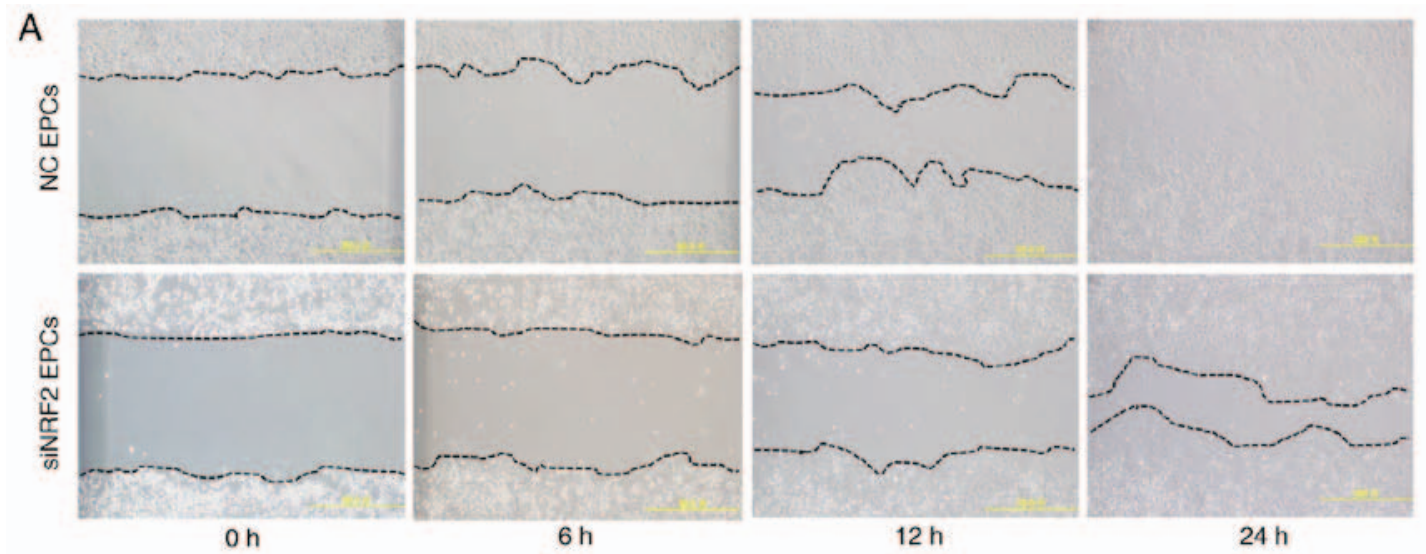

B

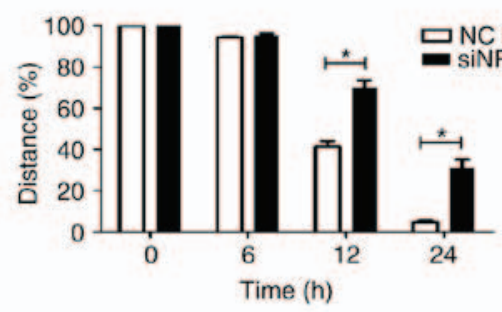

C
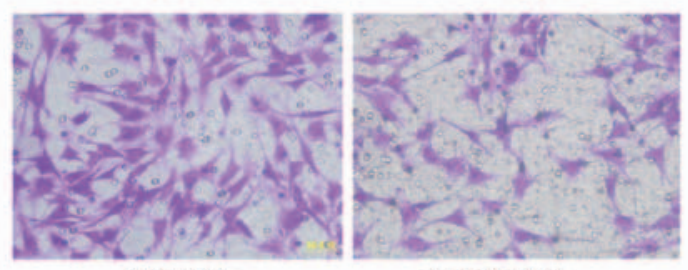

NC EPCs

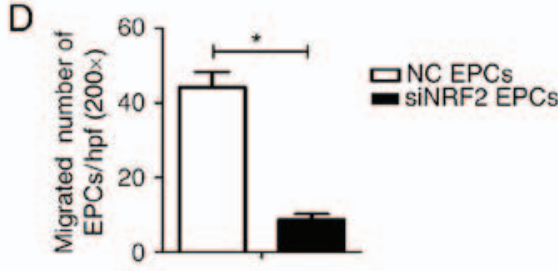

E

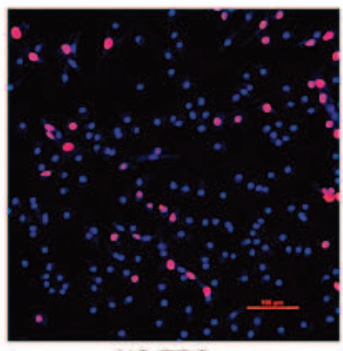

NC EPCs
SiNRF2 EPCs

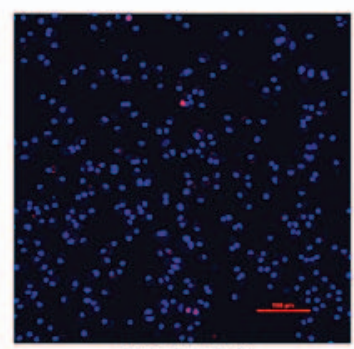

siNRF2 EPCs

G
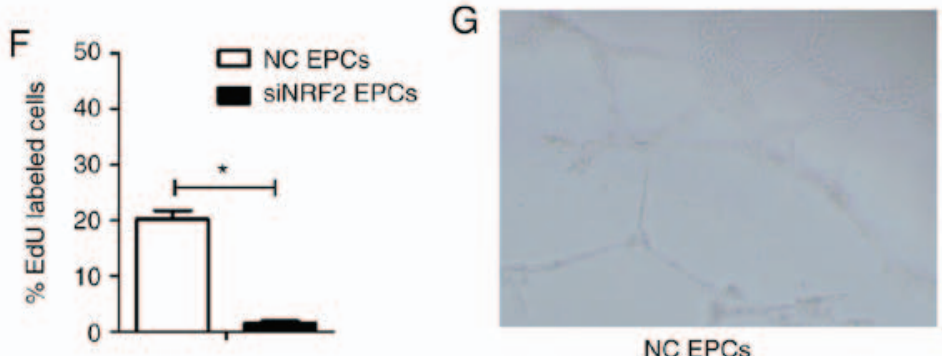

NC EPCs

siNRF2 EPCs
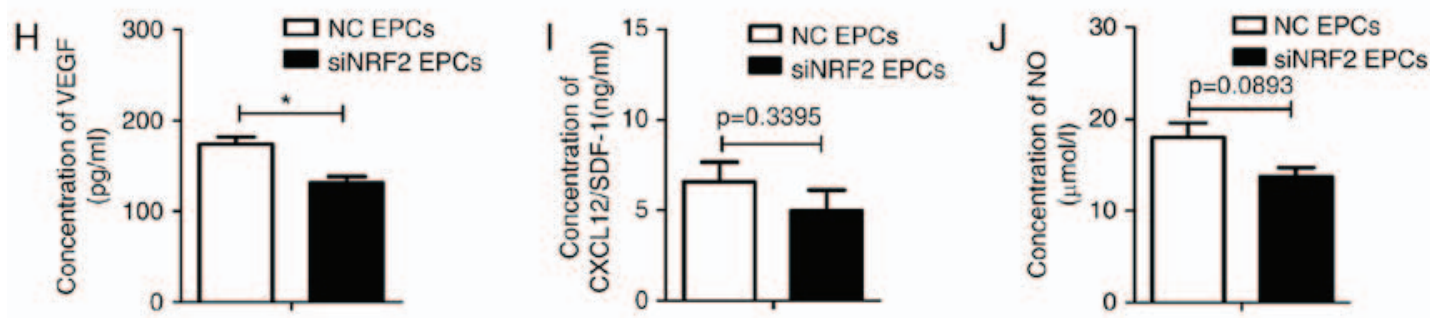

Figure 4. Nrf2 silencing reduces migration, proliferation, secretion and angiogenesis in EPCs. (A) Representative images and (B) quantification of wound healing assays with Nrf2-silenced EPCs and negative controls at 0, 6, 12 and $24 \mathrm{~h}$. Magnification, x100. The black dotted line shows the edge of the cell population. (C) Representative images and (D) quantification of crystal violet-stained migrated cells, as assessed by Transwell assay. Magnification, $\mathrm{x} 400$. (E) Representative images and (F) quantification of EdU staining (red), to measure the proliferative ability of Nrf2-silenced and control EPCs. Scale bar, $100 \mu \mathrm{m}$. (G) Representative images showing tube-forming activity. Magnification, x100. (H) Levels of secreted VEGF, (I) SDF-1 and (J) NO in the supernatant of cultured Nrf2-silenced and control EPCs. "P<0.05 compared with control ( $\mathrm{n}=4-6)$. Nrf2, nuclear factor erythroid 2-related factor 2; EPCs, endothelial progenitor cells; VEGF, vascular endothelial growth factor; SDF-1, stromal-derived factor-1; NO, nitric oxide; NC, negative control; si, small interfering.

Fig. 2A and B). The Transwell assay results also suggested that migration was significantly impaired in DM mice, with $8.67 \pm 1.50$ vs. $44.2 \pm 4.18$ migrated cells per field in the DM and control groups, respectively $(\mathrm{P}<0.05$; Fig. $2 \mathrm{C}$ and $\mathrm{D})$. An EdU assay was used to detect the proliferative ability of EPCs and the results demonstrated that proliferation was signifi- 

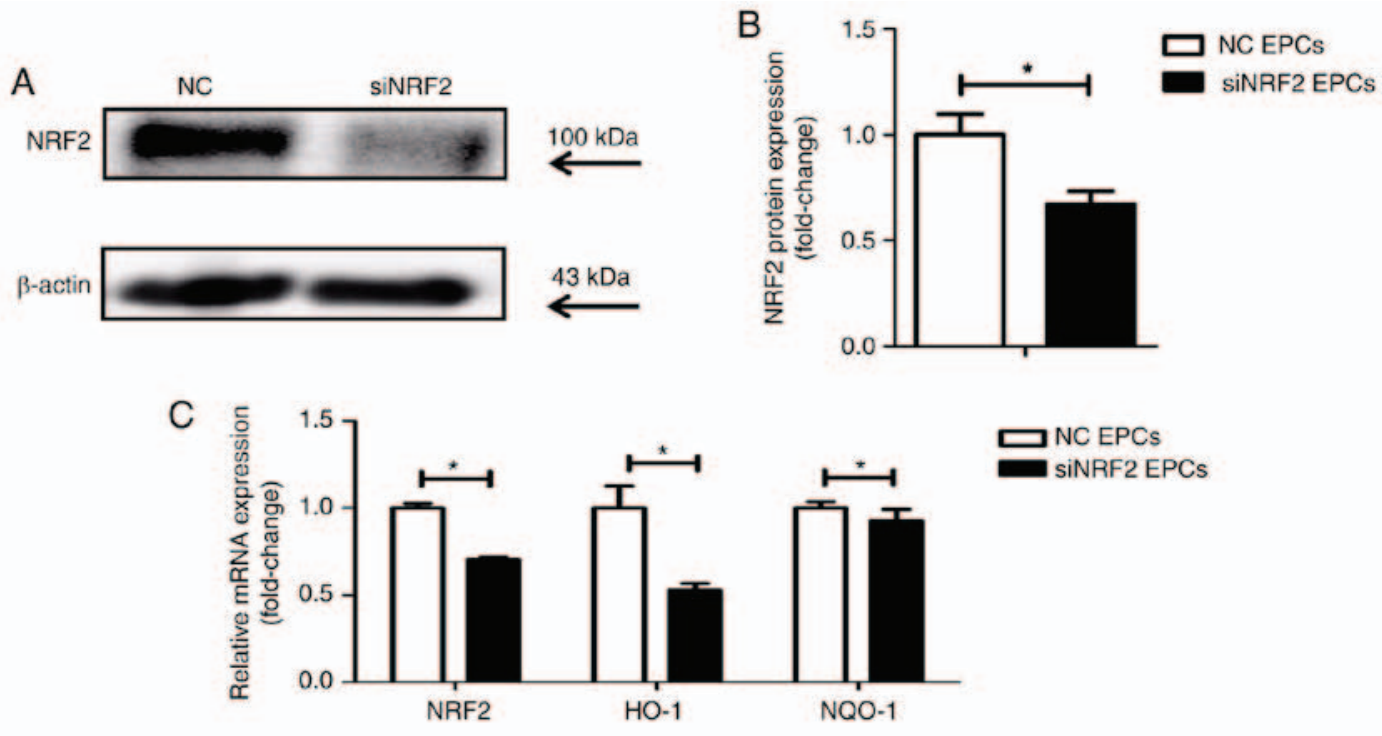

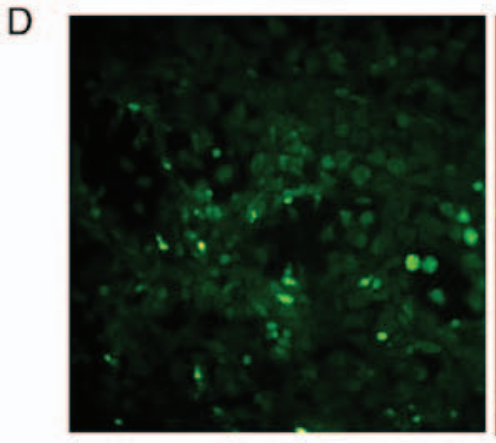

NC EPCS

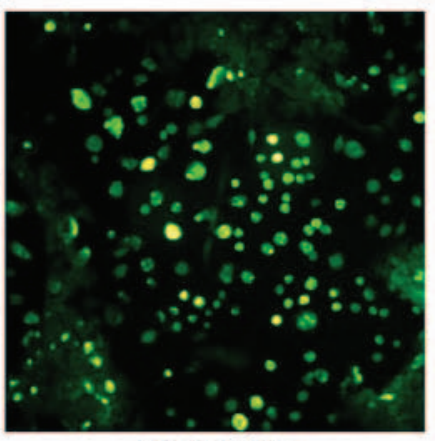

SiNRF2 EPCS

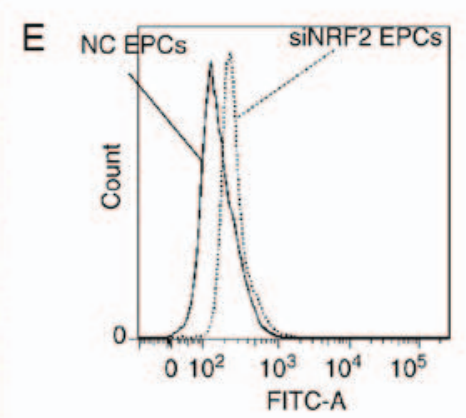

(n)
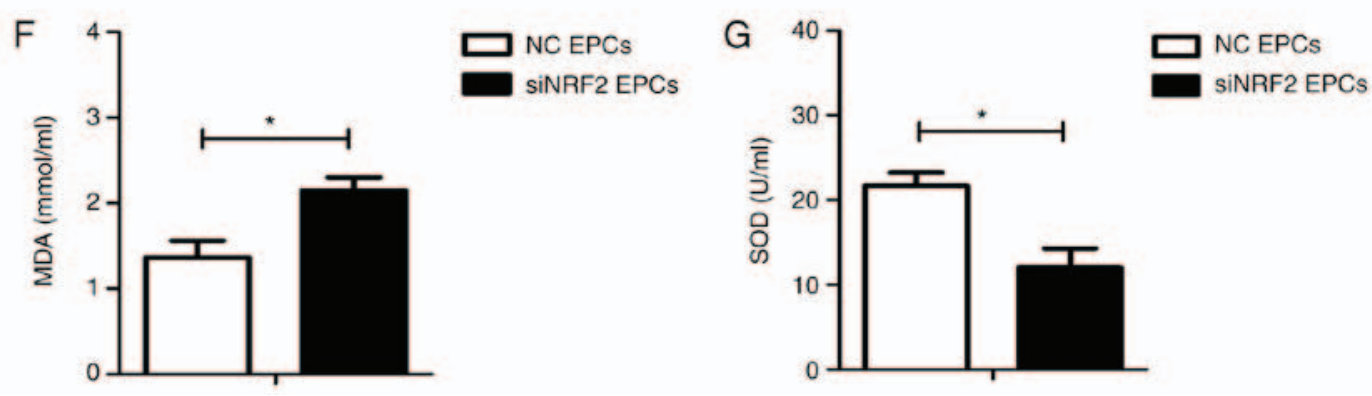

Figure 5. Nrf2 silencing increases the expression of ROS and MDA in EPCs, while SOD activity is downregulated. (A) Representative blots and (B) quantification of Nrf2 protein expression levels in Nrf2-silenced and control EPCs. (C) mRNA expression levels of Nrf2, HO-1 and NQO-1 in Nrf2-silenced and control EPCs. (D) Representative images from fluorescence microscopy analysis of ROS levels (green; magnification, x100). (E) Quantification of ROS levels as detected by flow cytometry. (F) Nrf2 silencing upregulated MDA levels and (G) decreased SOD activity in the supernatant of Nrf2-silenced EPCs. *P<0.05 compared with control ( $\mathrm{n}=8)$. Nrf2, nuclear factor erythroid 2-related factor 2; ROS, reactive oxygen species; MDA, malondialdehyde; EPCs, endothelial progenitor cells; SOD, superoxide dismutase; HO-1, heme oxygenase-1; NQO-1, quinone oxidoreductase-1; NC, negative control; si, small interfering.

cantly reduced in DM mice compared with the control group $(10.08 \pm 1.57 \%$ vs. $28.6 \pm 3.3 \%$ in DM and control groups respectively; $\mathrm{P}<0.05$; Fig. $2 \mathrm{E}$ and $\mathrm{F}$ ). Furthermore, tube-forming activity was decreased in DM EPCs compared with the control group (Fig. 2G), as was the secretion of VEGF, SDF and NO (Fig. 2H-J). These data indicate that DM decreased the migration, proliferation and secretion abilities of EPCs.

Nrf2 expression is decreased and oxidative stress levels are increased in DM EPCs. ROS levels were markedly increased in EPCs derived from DM mice compared with control EPCs, as assessed by fluorescence detection (Fig. 3A) and flow cytometry analysis (Fig. 3B). The levels of MDA were increased and SOD activity was decreased in the supernatant of DM EPCs (Fig. 3C and D). Nrf2 expression was decreased significantly in DM EPCs at the protein (Fig. 3E and F) and mRNA levels (Fig. 3G), compared with healthy EPCs. In addition, the mRNA expression levels of HO-1 and NQO-1 were also significantly decreased in DM EPCs (Fig. 3G). These results indicate that DM increased oxidative stress and decreased Nrf2 expression in EPCs.

Nrf2 silencing impairs the migration, proliferation, secretion and angiogenesis functions of EPCs. To investigate the role 
A
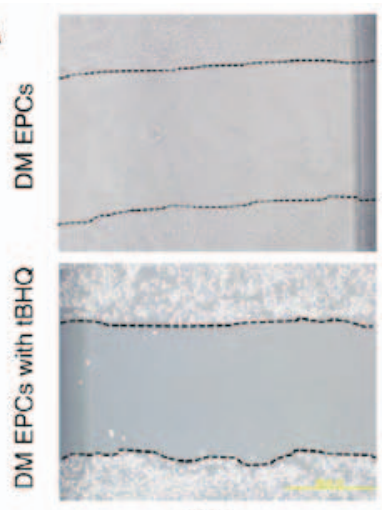

$\mathrm{Oh}$

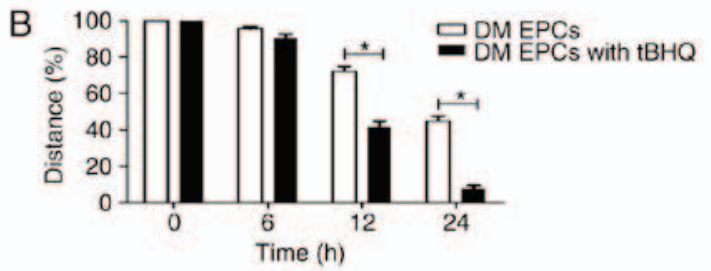

D
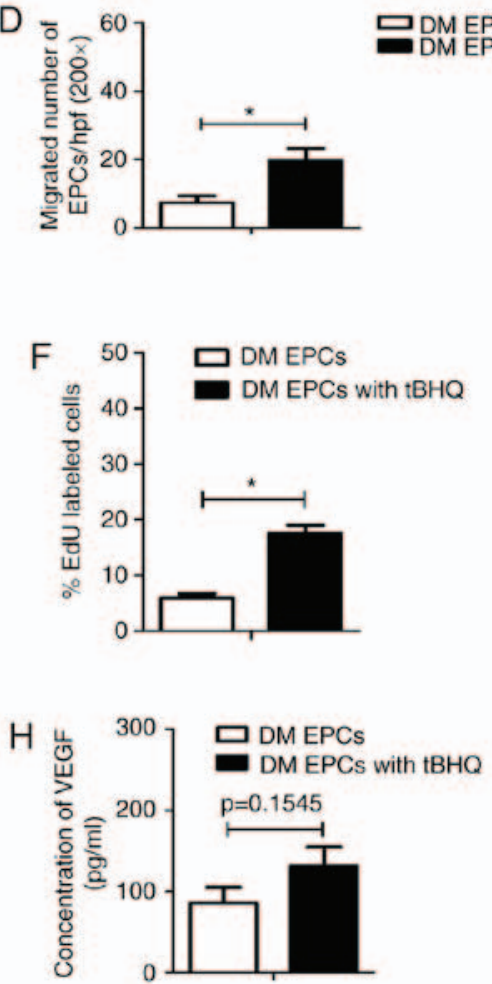

E

\section{G}
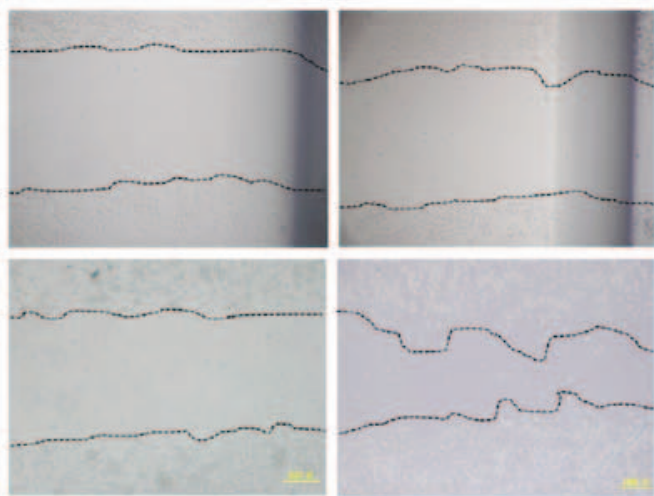

$6 \mathrm{~h}$

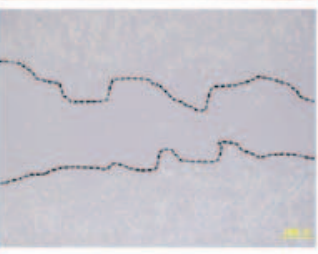

$12 \mathrm{~h}$
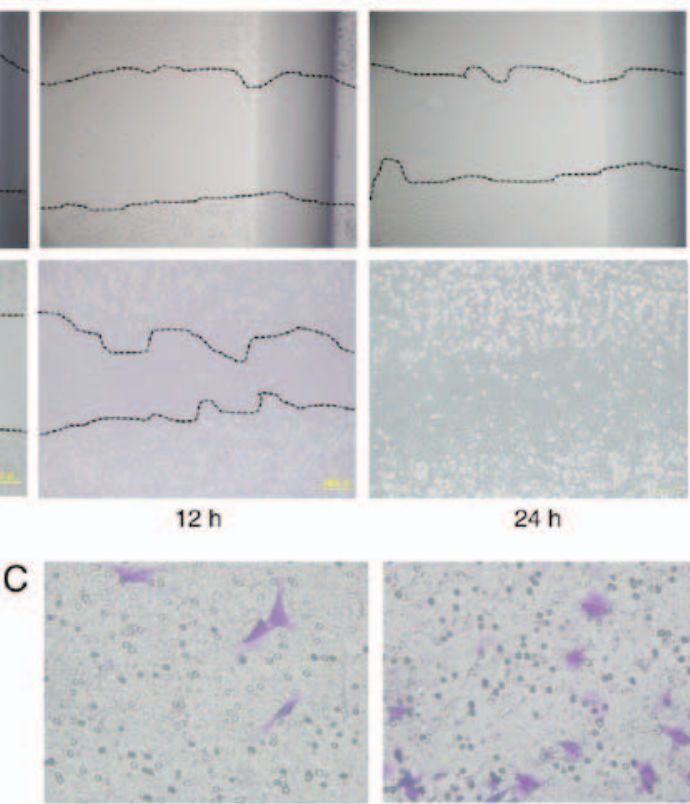

DM EPCs

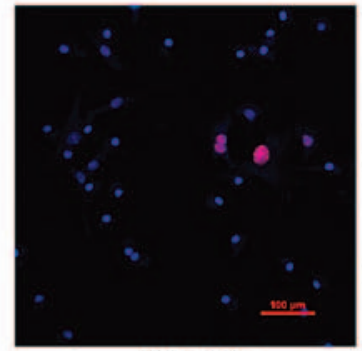

DM EPCs

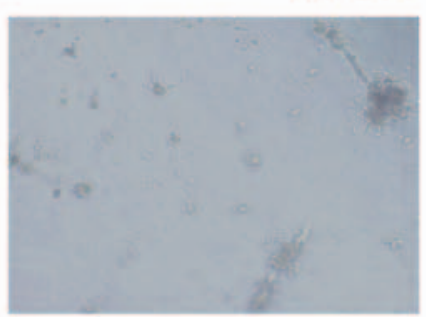

DM EPCs

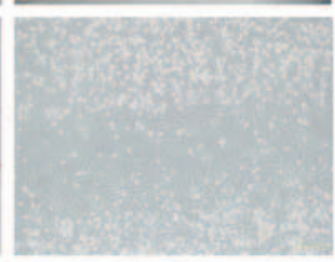

$24 \mathrm{~h}$

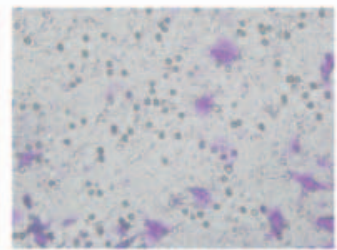

DM EPCs with tBHQ

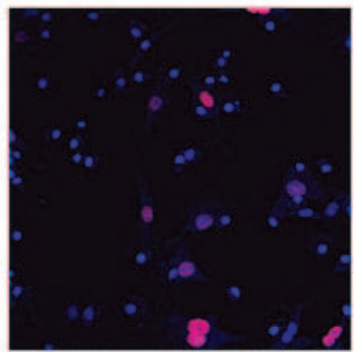

DM EPCs with $\mathrm{tBHQ}$

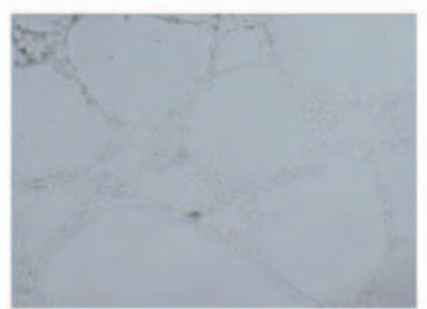

DM EPCs with $\mathrm{BBHQ}$
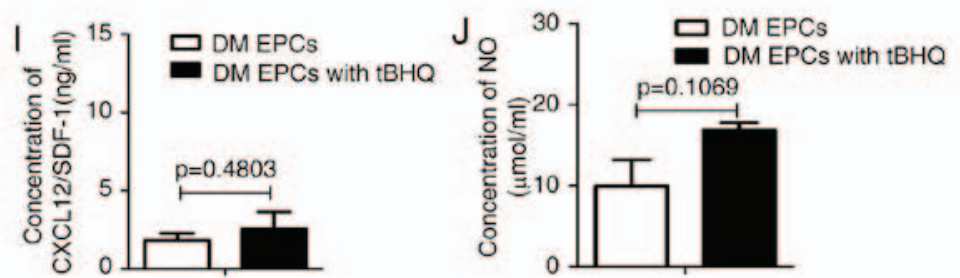

Figure 6. Nrf2 activation by tBHQ improves migration, proliferation, secretion and angiogenesis in diabetic EPCs. (A) Representative images and (B) quantification of wound healing assays with DM EPCs treated with Nrf2 activator tBHQ for 0, 6, 12 and 24 h. Magnification, x100. The black dotted line shows the edge of the cell population. (C) Representative images and (D) quantification of crystal violet-stained migrated cells, as assessed by Transwell assay. Magnification, x400. (E) Representative images and (F) quantification of EdU staining (red), to measure the proliferative ability of Nrf2-activated DM EPCs. Scale bar, $100 \mu \mathrm{m}$. (G) Representative images showing tube-forming activity. Magnification, x100. (H) Levels of secreted VEGF, (I) SDF-1 and (J) NO in the supernatant of cultured DM EPCs treated with tBHQ. * $\mathrm{P}<0.05$ compared with control ( $\mathrm{n}=4-6)$. Nrf2, nuclear factor erythroid 2-related factor 2; tBHQ, tert-Butylhydroquinone; EPCs, endothelial progenitor cells; DM, diabetes mellitus; VEGF, vascular endothelial growth factor; SDF-1, stromal-derived factor- 1 ; NO, nitric oxide.

of Nrf2 in regulating the biological function of EPCs, Nrf2 expression was silenced in normal bone marrow-derived EPCs via siRNA transfection. Nrf2-silenced EPCs had decreased migratory abilities (Fig. 4A-D), proliferative capacity (Fig. 4E and F), and tube-forming activity (Fig. 4G), as well as lower
VEGF secretion (Fig. 4H), compared with the negative controls. SDF-1 and NO levels were lower in the Nrf2-silenced EPCs, however these data were not statistically significant (Fig. 4I and J). Collectively, the functionality of EPCs was reduced following Nrf2 silencing. 
A

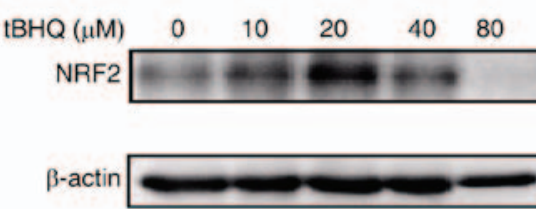

C

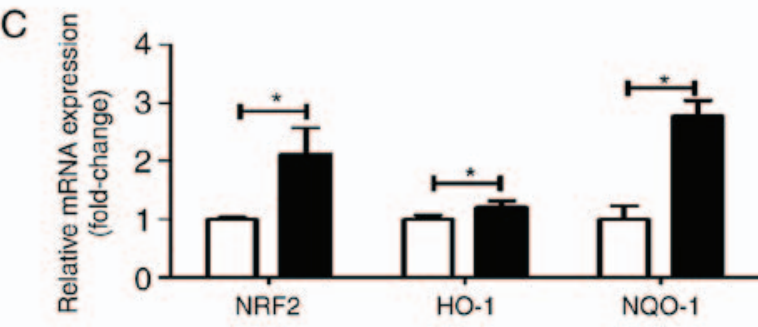

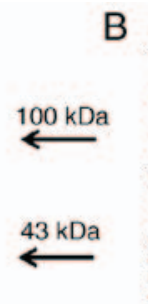

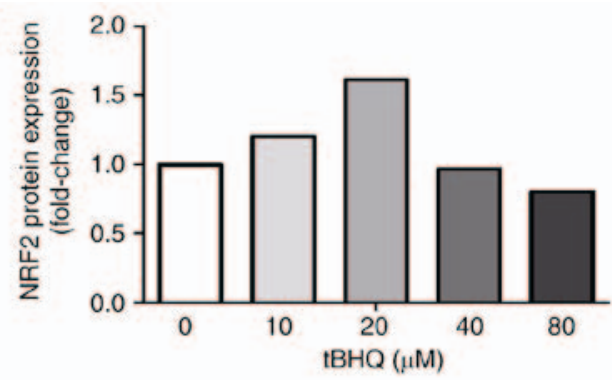

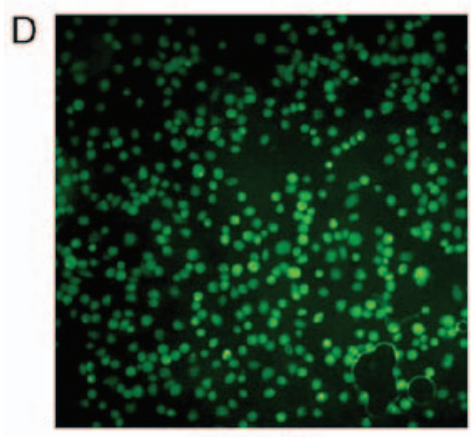

DM EPCS

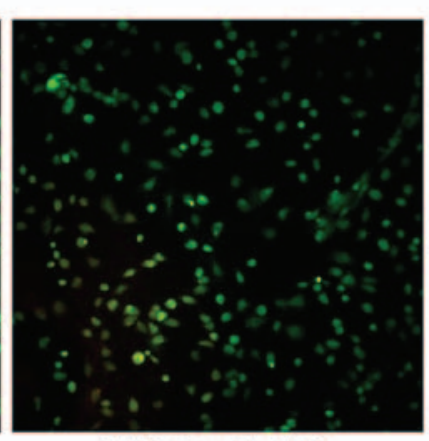

DM EPCs with $\mathrm{BBHQ}$
$\mathrm{E}$

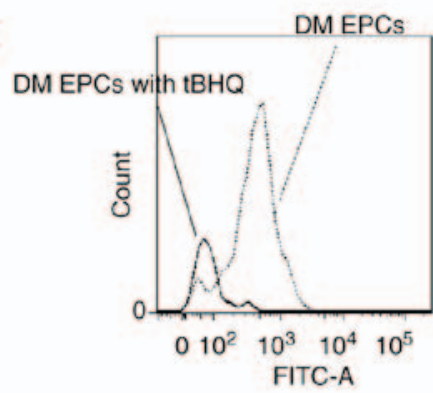

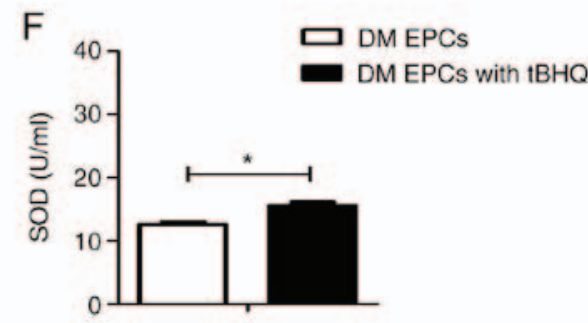

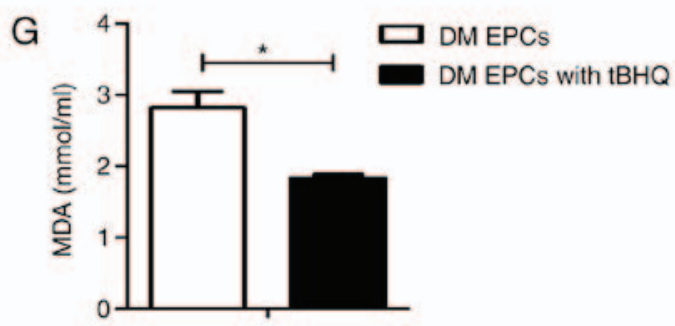

Figure 7. tBHQ protects against oxidative stress in EPCs derived from DM mice. (A) Representative images and (B) quantification of Nrf2 protein expression levels in tBHQ-treated DM EPCs. (C) mRNA expression levels of Nrf2, HO-1 and NQO-1 in Nrf2-activated DM EPCs. (D) Representative images from fluorescence microscopy analysis of ROS levels (green; magnification, x100). (E) Quantification of ROS levels as detected by flow cytometry. (F) MDA expression was decreased and (G) SOD activity was increased in the supernatant of DM EPCs treated with tBHQ compared with untreated controls. "P<0.05 compared with control $(\mathrm{n}=8)$. tBHQ, tert-Butylhydroquinone; EPCs, endothelial progenitor cells; DM, diabetes mellitus; Nrf2, nuclear factor erythroid 2-related factor 2; HO-1, heme oxygenase-1; NQO-1, quinone oxidoreductase-1; MDA, malondialdehyde; SOD, superoxide dismutase.

Nrf2 silencing upregulates ROS and MDA, and decreases the activity of SOD in EPCs. Nrf2 silencing was achieved by transfection with siRNA (Fig. 5A and B). Following Nrf2 silencing in the EPCs, the mRNA expression levels of HO-1 and NQO-1 were reduced (Fig. 5C), while ROS production was increased (Fig. 5D and E), compared with the negative controls. In addition, Nrf2 silencing significantly increased the expression of MDA and decreased SOD activity in the supernatant of EPCs (Fig. 5F and G).

$N r f 2$ activation by $t B H Q$ improves the migration, proliferation and secretion of DM EPCs. To determine whether Nrf2 serves an important role in EPCs, the effect of Nrf2 activation by tBHQ, a validated Nrf2 inducer (33), was assessed on the biological function of EPCs from DM mice. The migratory ability (Fig. 6A-D), proliferative capacity (Fig. 6E and F) and tube-forming activity (Fig. 6G) of DM EPCs were increased following Nrf2 activation (with $20 \mu \mathrm{M}$ tBHQ), compared with untreated DM EPCs. In addition, tBHQ-treated DM-EPCs displayed a trend to increased VEGF, SDF-1 and NO secretion, although these results were not statistically significant (Fig. 6H-J). Collectively, these results suggest that $\mathrm{tBHQ}$-mediated Nrf2 activation improved the migration, proliferation and secretion capacity of DM EPCs.

tBHQ protects against oxidative stress in DM-EPCs. Following treatment with tBHQ, EPCs isolated from DM mice had higher Nrf2 expression at the protein (Fig. 7A and B) and mRNA level (Fig. 7C). In addition, HO-1 and NQO-1 mRNA expression levels were increased in tBHQ-treated DM EPCs 
A

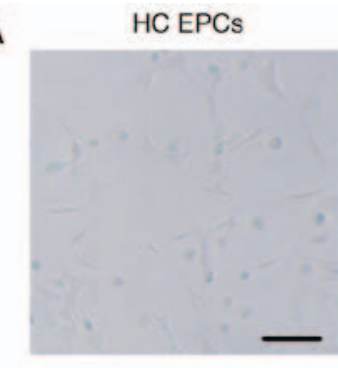

C

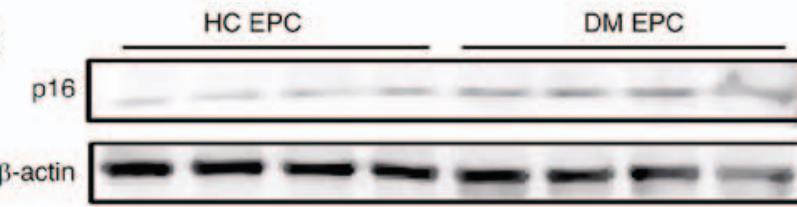

DM EPCs with $t B H Q$

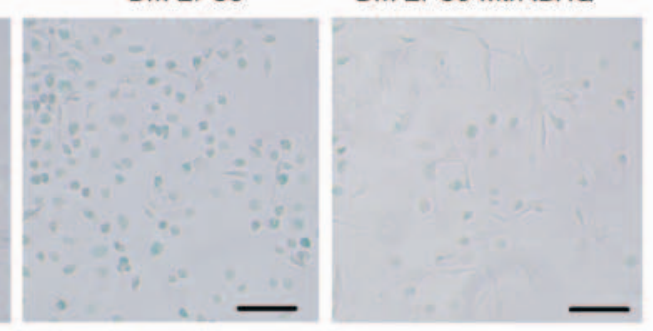

F

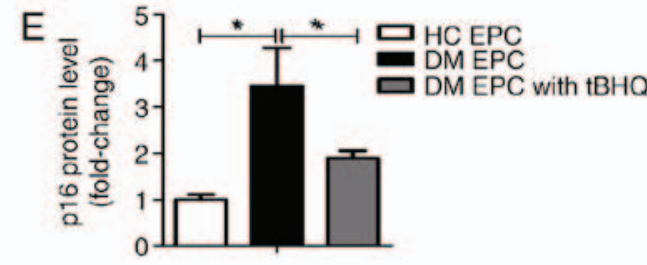

G
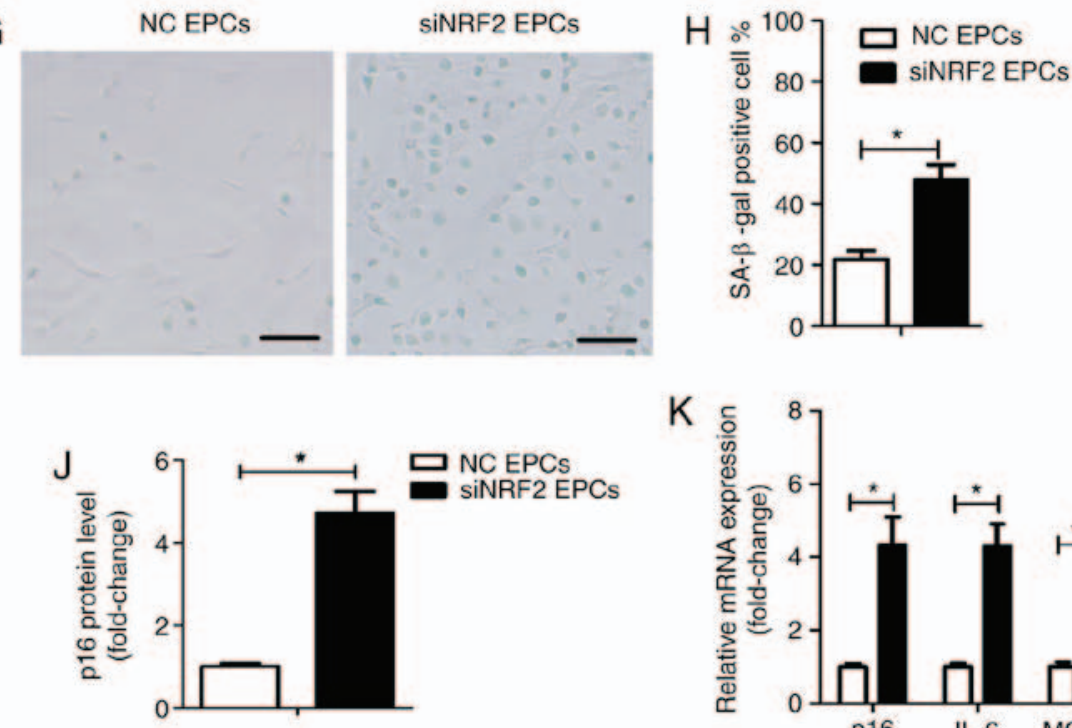
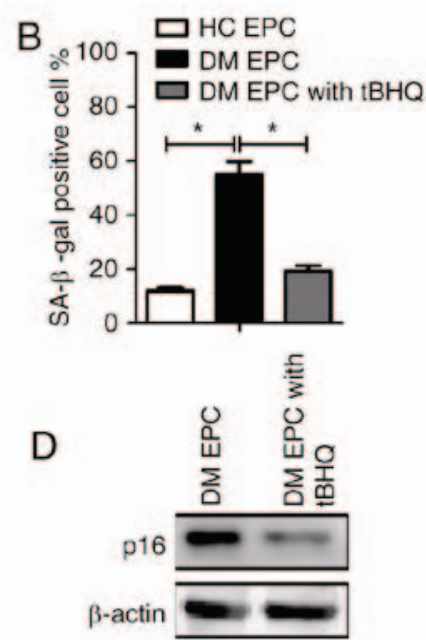

$\beta$-actin
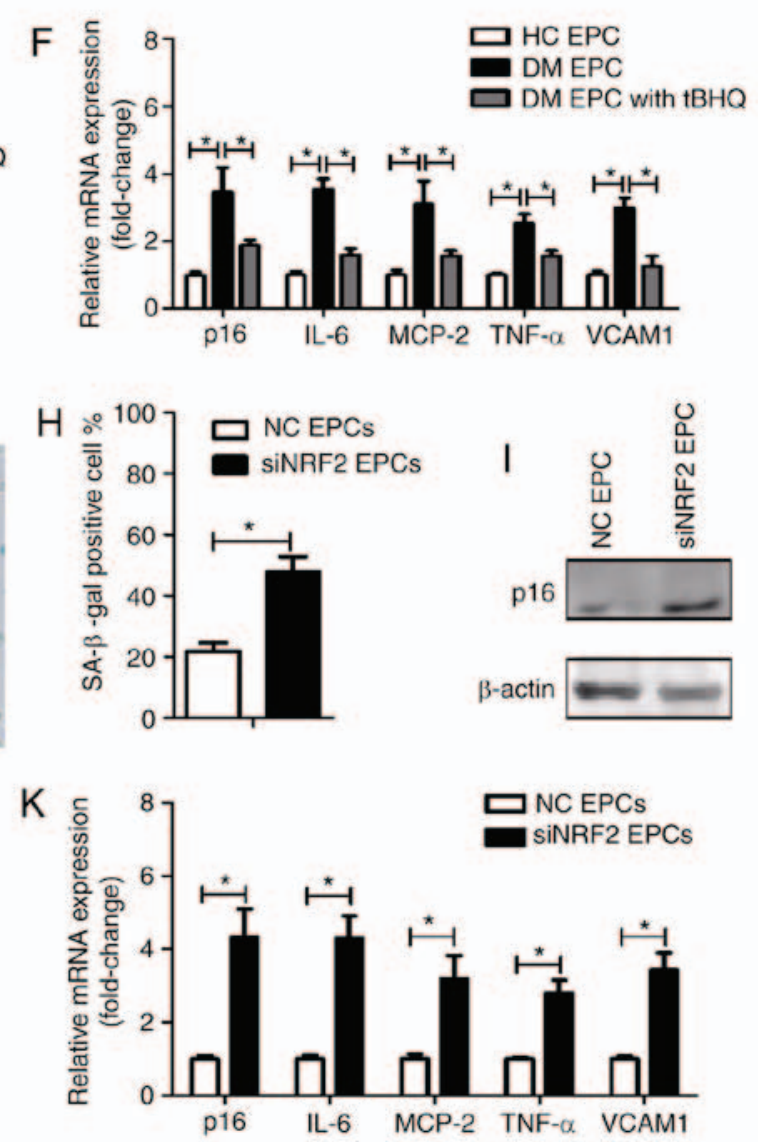

Figure 8. Nrf2 regulates EPC senescence in DM mice. (A) Representative images and (B) quantification of $\beta$-gal staining of HC EPCs, DM EPCs and DM EPCs treated with tBHQ. Scale bar, $100 \mu \mathrm{m}$. (C-E) Expression levels of p16 protein in HC EPCs, DM EPCs and DM EPCs treated with tBHQ. (F) mRNA expression levels of p16, IL-6, MCP-2, TNF- $\alpha$ and VCAM1 in HC EPCs, DM EPCs and DM EPCs treated with tBHQ. (G) Representative images and (H) quantification of $\beta$-gal staining of NC EPCs and siNRF2 EPCs. Scale bar, $100 \mu \mathrm{m}$. (I) Representative blots and (J) quantification of p16 protein expression levels in NC EPCs and siNRF2 EPCs. (K) mRNA expression levels of p16, IL-6, MCP-2, TNF- $\alpha$, and VCAM1 in NC EPCs and siNRF2 EPCs. "P<0.05, with comparisons indicated by lines $(\mathrm{n}=4-6)$. Nrf2, nuclear factor erythroid 2-related factor 2; EPCs, endothelial progenitor cells; DM, diabetes mellitus; HC, healthy control; tBHQ, tert-Butylhydroquinone; IL, interleukin; MCP, monocyte chemotactic protein; TNF, tumor necrosis factor; VCAM1, vascular cell adhesion molecule 1; $\mathrm{NC}$, negative control; si, small interfering.

compared with untreated DM EPCs (Fig. 7C), while ROS production was decreased (Fig. 7D and E). MDA expression was decreased and SOD activity was increased in the supernatant of DM EPCs treated with tBHQ compared with untreated cells (Fig. 7F and G). These results indicate that tBHQ has the potential to ameliorate oxidative stress in DM EPCs.
Nrf 2 regulates the senescence of EPCs in DM mice. To explore the underlying mechanism by which $\mathrm{tBHQ}$ protects against damage in DM-EPCs, the senescence of EPCs was assessed using an SA- $\beta$-gal assay, and by evaluating p16 expression (34) and senescence-associated secretory phenotype (SASP) $(34,35)$. SASP was evaluated by measuring the mRNA 
expression levels of IL-6, MCP-2, TNF- $\alpha$ and VCAM1. As illustrated in Fig. 8A and B, DM EPCs exhibited increased $\beta$-gal-positive cell staining compared with the control group, while tBHQ treatment reversed this effect. In addition, p16 and SASP expression was increased in DM EPCs compared with the control group, and this effect was significantly reversed by tBHQ treatment (Fig. 8C-F). In normal healthy EPCs, an increased number of $\beta$-gal-positive cells were observed following Nrf2 silencing (Fig. 8G and H), and p16 and SASP were increased (Fig. 8I-K). The results suggest that Nrf2 negatively regulated the senescence of EPCs.

\section{Discussion}

The results of the present study revealed that DM reduced the expression of Nrf2, which was accompanied by enhanced oxidative stress, senescence and dysfunction in EPCs. Nrf2 activation protected DM EPCs against oxidative stress and ameliorated the biological dysfunction and senescence of DM EPCs. These results suggest that Nrf2 may serve a vital role in regulating EPC survival and maintaining functionality under oxidative stress via modifying cell senescence.

Patients with DM often experience serious complications, including CVD, diabetic retinopathy and diabetic nephropathy, which can cause death or blindness. Some EPC subtypes have been considered as potential therapeutic modalities for DM complications $(36,37)$. Boyko et al $(38)$ reported that the emergence of arterial disease is the only limb-specific risk factors for amputation in DM, and EPCs contribute to postnatal neovascularization and endothelial repair. Thus, therapeutic interventions using EPCs may be a promising strategy for the management of DM. Previous studies have indicated that DM is able to downregulate the number of circulating EPCs in humans $(4,39,40)$ and in animals $(28,41,42)$. In addition, proliferation, colony formation, tube formation, self-renewal and mobilization in DM EPCs were reduced $(41,43)$. In the present study, EPCs isolated from STZ-induced DM mice displayed decreased functionality, including inhibited migration, proliferation and angiogenesis abilities, as well as reduced secretion of NO, VEGF and SDF-1 $\alpha$, all of which are important for the vascular recruitment repair in DM. These results were consistent with the previous report (39-43). NO release is essential for the survival, migration, and other biological functions of EPCs. It had been proposed that VEGF and SDF-1 $\alpha$ act together to stimulate angiogenic processes (44), both of which are also implicated in EPC mobilization.

To further explore the potential mechanisms by which DM inhibits EPC functionality, the levels of oxidative stress in DM EPCs were assessed. The results revealed that EPC impairment in DM may be associated with oxidative stress, with increased ROS and MDA content and decreased SOD activity. Nrf2 regulates the response of cells to oxidative stress; activated Nrf2 translocates into the nucleus, binds to antioxidant response elements and activates the transcription of target antioxidant genes, including HO-1, to counteract ROS (45). It has been reported that Nrf 2 knockdown reduces the biofunction of endothelial cells, while angiogenic factors can promote tube formation in endothelial cells via activating Nrf2 and increasing expression of its target gene, HO-1 (46). Increasing Nrf2 activity and its downstream target genes protects against EPC damage in DM, and the protective role of SDF-1 is reduced by silencing Nrf2 (22). Nrf2 serves an important role in the angiogenesis of EPCs, especially when cells are under oxidative stress (47). Previous reports have demonstrated that Nrf2 is downregulated in the nuclei of EPCs under high glucose treatment, including in DM $(48,49)$. In the present study, total Nrf2 expression was decreased in DM EPCs compared with the control group. Furthermore, prototype Nrf2 target genes, NQO1 and HO-1, were downregulated, which is consistent with previous studies. Overall, Nrf2 may modify the oxidative stress and participate in the diabetes-induced damages of EPCs.

Previous research has suggested that Nrf2 increases the lifespan in Caenorhabditis elegans (50) and regulates neural stem cells during aging (51). Based on this, the present study next explored whether senescence serves a role in the pathogenesis of DM EPCs. The results revealed that DM accelerated EPC senescence and reduced the expression and activity of Nrf2. Silencing of Nrf2 resulted in an increase in normal EPC senescence, while Nrf2 overexpression downregulated senescence in DM EPCs and ameliorated functional impairments. Based on these results, it can be concluded that Nrf2 serves a protective role in ameliorating cell senescence in DM. You et al (23) reported that curcumin modulates the function of endothelial progenitor cells and can activate the Nrf2 signaling pathway (52). Nrf2 may be an effective target for the prevention or treatment of DM complications, reducing diabetic amputation risk by regulating EPC dysfunction.

In summary, the present study demonstrated that Nrf2 protected against DM-induced EPC dysfunction due to oxidative stress, possibly via ameliorating cell senescence. These results suggest that targeting Nrf2 may be a promising therapeutic method for the treatment and prevention of diabetes-induced endothelial dysfunction and microangiopathy, potentially reducing the risk of complications associated with DM.

\section{Acknowledgements}

Not applicable.

\section{Funding}

This work was supported by the Natural Science Foundation of China (grant no. 81571373) and the Natural Science Foundation of Hubei Province (grant no. 2017CFB627).

\section{Availability of data and materials}

The analyzed datasets generated during the study are available from the corresponding author on reasonable request.

\section{Authors' contributions}

RYW designed and performed the study, analyzed the data and wrote the manuscript. LHL and LZ contributed to writing the manuscript. HL, KFW and JA were involved in performing the study. QW, YL, LJB and BMQ contributed to data analysis and interpretation. BLQ conceived the study, participated in its design and helped to draft the manuscript. All authors read and approved the final manuscript. 


\section{Ethics approval and consent to participate}

All experiments were approved by the Ethics Committee of Tongji Medical College, Huazhong University of Science and Technology.

\section{Patient consent for publication}

Not applicable.

\section{Competing interests}

The authors declare that they have no competing interests.

\section{References}

1. Abplanalp WT, Conklin DJ, Cantor JM, Ginsberg MH, Wysoczynski M, Bhatnagar A and O'Toole TE: Enhanced integrin $\alpha 4 \beta 1$-mediated adhesion contributes to a mobilization defect of endothelial progenitor cells in diabetes. Diabetes 65: 3505-3515, 2016.

2. Soedamah-Muthu SS, Fuller JH, Mulnier HE, Raleigh VS, Lawrenson RA and Colhoun HM: High risk of cardiovascular disease in patients with type 1 diabetes in the U.K.: A cohort study using the general practice research database. Diabetes Care 29: 798-804, 2006.

3. Georgescu A: Vascular dysfunction in diabetes: The endothelial progenitor cells as new therapeutic strategy. World J Diabetes 2 : 92-97, 2011.

4. Fadini GP, Sartore S, Albiero M, Baesso I, Murphy E, Menegolo M, Grego F, Vigili de Kreutzenberg S, Tiengo A, Agostini C and Avogaro A: Number and function of endothelial progenitor cells as a marker of severity for diabetic vasculopathy. Arterioscler Thromb Vasc Biol 26: 2140-2146, 2006.

5. Asahara T, Murohara T, Sullivan A, Silver M, van der Zee R, Li T, Witzenbichler B, Schatteman G and Isner JM: Isolation of putative progenitor endothelial cells for angiogenesis. Science 275: 964-967, 1997.

6. Zampetaki A, Kirton JP and Xu Q: Vascular repair by endothelial progenitor cells. Cardiovasc Res 78: 413-421, 2008.

7. Williamson K, Stringer SE and Alexander MY: Endothelial progenitor cells enter the aging arena. Front Physiol 3: 30, 2012.

8. Hung HS, Shyu WC, Tsai CH,Hsu SH and Lin SZ: Transplantation of endothelial progenitor cells as therapeutics for cardiovascular diseases. Cell Transplant 18: 1003-1012, 2009.

9. Bhatwadekar AD, Shaw LC and Grant MB: Promise of endothelial progenitor cell for treatment of diabetic retinopathy. Expert Rev Endocrinol Metab 5: 29-37, 2010.

10. Cantrell D: T cell antigen receptor signal transduction pathways. Annu Rev Immunol 14: 259-274, 1996.

11. Dinkova-Kostova AT, Holtzclaw WD, Cole RN, Itoh K, Wakabayashi N, Katoh Y, Yamamoto M and Talalay P: Direct evidence that sulfhydryl groups of Keapl are the sensors regulating induction of phase 2 enzymes that protect against carcinogens and oxidants. Proc Natl Acad Sci USA 99: 11908-11913, 2002.

12. Itoh K, Wakabayashi N, Katoh Y, Ishii T, Igarashi K, Engel JD and Yamamoto M: Keap1 represses nuclear activation of antioxidant responsive elements by Nrf2 through binding to the amino-terminal Neh2 domain. Genes Dev 13: 76-86, 1999.

13. McMahon $M$, Itoh $K$, Yamamoto $M$ and Hayes JD: Keap1-dependent proteasomal degradation of transcription factor Nrf2 contributes to the negative regulation of antioxidant response element-driven gene expression. J Biol Chem 278: 21592-21600, 2003.

14. Itoh K, Chiba T, Takahashi S, Ishii T, Igarashi K, Katoh Y, Oyake T, Hayashi N, Satoh K, Hatayama I, et al: An Nrf2/small Maf heterodimer mediates the induction of phase II detoxifying enzyme genes through antioxidant response elements. Biochem Biophys Res Commun 236: 313-322, 1997.

15. Kensler TW, Wakabayashi N and Biswal S: Cell survival responses to environmental stresses via the Keap1-Nrf2-ARE pathway. Annu Rev Pharmacol Toxicol 47: 89-116, 2007.
16. Venugopal R and Jaiswal AK: Nrf1 and Nrf2 positively and c-Fos and Fra1 negatively regulate the human antioxidant response element-mediated expression of NAD $(\mathrm{P}) \mathrm{H}$ : Quinone oxidoreductase1 gene. Proc Natl Acad Sci USA 93: 14960-14965, 1996.

17. Lee JM, Li J, Johnson DA, Stein TD, Kraft AD, Calkins MJ, Jakel RJ and Johnson JA: Nrf2, a multi-organ protector? FASEB J 19: 1061-1066, 2005.

18. Li W and Kong AN: Molecular mechanisms of Nrf2-mediated antioxidant response. Mol Carcinog 48: 91-104, 2009.

19. Maher JM, Dieter MZ, Aleksunes LM, Slitt AL, Guo G, Tanaka Y, Scheffer GL, Chan JY, Manautou JE, Chen Y, et al: Oxidative and electrophilic stress induces multidrug resistance-associated protein transporters via the nuclear factor-E2-related factor-2 transcriptional pathway. Hepatology 46: 1597-1610, 2007.

20. Kim HJ and Nel AE: The role of phase II antioxidant enzymes in protecting memory $\mathrm{T}$ cells from spontaneous apoptosis in young and old mice. J Immunol 175: 2948-2959, 2005.

21. Thimmulappa RK, Scollick C, Traore K, Yates M, Trush MA, Liby KT, Sporn MB, Yamamoto M, Kensler TW and Biswal S: Nrf2-dependent protection from LPS induced inflammatory response and mortality by CDDO-Imidazolide. Biochem Biophys Res Commun 351: 883-889, 2006.

22. Dai X, Yan X, Zeng J, Chen J, Wang Y, Chen J, Li Y, Barati MT, Wintergerst KA, Pan K, et al: Elevating CXCR7 improves angiogenic function of EPCs via Akt/GSK-3 $\beta /$ Fyn-Mediated Nrf2 activation in diabetic limb ischemia. Circ Res 120: e7-e23, 2017.

23. You J, Sun J, Ma T, Yang Z, Wang X, Zhang Z, Li J, Wang L, Ii M, Yang $J$ and Shen $Z$ : Curcumin induces therapeutic angiogenesis in a diabetic mouse hindlimb ischemia model via modulating the function of endothelial progenitor cells. Stem Cell Res Ther 8: $182,2017$.

24. Li H, Zhang X, Guan X, Cui X, Wang Y, Chu H and Cheng M: Advanced glycation end products impair the migration, adhesion and secretion potentials of late endothelial progenitor cells. Cardiovasc Diabetol 11: 46, 2012.

25. Sorrentino SA, Bahlmann FH, Besler C, Müller M, Schulz S, Kirchhoff N, Doerries C, Horváth T, Limbourg A, Limbourg F, et al: Oxidant stress impairs in vivo reendothelialization capacity of endothelial progenitor cells from patients with type 2 diabetes mellitus: Restoration by the peroxisome proliferator-activated receptor-gamma agonist rosiglitazone. Circulation 116: 163-173, 2007.

26. Landmesser U, Engberding N, Bahlmann FH, Schaefer A, Wiencke A, Heineke A, Spiekermann S, Hilfiker-Kleiner D, Templin C, Kotlarz D, et al: Statin-induced improvement of endothelial progenitor cell mobilization, myocardial neovascularization, left ventricular function, and survival after experimental myocardial infarction requires endothelial nitric oxide synthase. Circulation 110: 1933-1939, 2004.

27. Bahlmann FH, De Groot K, Spandau JM, Landry AL, Hertel B, Duckert T, Boehm SM, Menne J, Haller H and Fliser D: Erythropoietin regulates endothelial progenitor cells. Blood 103: 921-926, 2004.

28. Wu Q, Qi B, Liu Y, Cheng B, Liu L, Li Y and Wang Q: Mechanisms underlying protective effects of trimetazidine on endothelial progenitor cells biological functions against $\mathrm{H} 2 \mathrm{O} 2$-induced injury: Involvement of antioxidation and Akt/eNOS signaling pathways. Eur J Pharmacol 707: 87-94, 2013.

29. Kuliszewski MA, Ward MR, Kowalewski JW, Smith AH, Stewart DJ, Kutryk MJ and Leong-Poi H: A direct comparison of endothelial progenitor cell dysfunction in rat metabolic syndrome and diabetes. Atherosclerosis 226: 58-66, 2013.

30. Asahara T, Takahashi T, Masuda H, Kalka C, Chen D, Iwaguro H, Inai Y, Silver M and Isner JM: VEGF contributes to postnatal neovascularization by mobilizing bone marrow-derived endothelial progenitor cells. EMBO J 18: 3964-3972, 1999.

31. Li WD, Hu N, Lei FR, Wei S, Rong JJ, Zhuang H and Li XQ: Autophagy inhibits endothelial progenitor cells migration via the regulation of MMP2, MMP9 and uPA under normoxia condition. Biochem Biophys Res Commun 466: 376-380, 2015.

32. Livak KJ and Schmittgen TD: Analysis of relative gene expression data using real-time quantitative PCR and the 2(-Delta Delta C(T)) method. Methods 25: 402-408, 2001.

33. Takaya K, Suzuki T, Motohashi H, Onodera K, Satomi S, Kensler TW and Yamamoto M: Validation of the multiple sensor mechanism of the Keap1-Nrf2 system. Free Radic Biol Med 53: 817-827, 2012. 
34. Wang R, Yu Z, Sunchu B, Shoaf J, Dang I, Zhao S, Caples K, Bradley L, Beaver LM, Ho E, et al: Rapamycin inhibits the secretory phenotype of senescent cells by a Nrf2-independent mechanism. Aging Cell 16: 564-574, 2017.

35. D'Apolito M, Colia AL, Lasalvia M, Capozzi V, Falcone MP, Pettoello-Mantovani M, Brownlee M, Maffione AB and Giardino I: Urea-induced ROS accelerate senescence in endothelial progenitor cells. Atherosclerosis 263: 127-136, 2017.

36. Lois N, McCarter RV, O'Neill C, Medina RJ and Stitt AW: Endothelial progenitor cells in diabetic retinopathy. Front Endocrinol (Lausanne) 5: 44, 2014.

37. Foresti R, Bucolo C, Platania CM, Drago F, Dubois-Randé JL and Motterlini R: Nrf2 activators modulate oxidative stress responses and bioenergetic profiles of human retinal epithelial cells cultured in normal or high glucose conditions. Pharmacol Res 99: 296-307, 2015.

38. Boyko EJ, Seelig AD and Ahroni JH: Limb- and person-level risk factors for lower-limb amputation in the prospective seattle diabetic foot study. Diabetes Care 41: 891-898, 2018.

39. Hörtenhuber T, Rami-Mehar B, Satler M, Nagl K, Höbaus C, Höllerl F, Koppensteiner R, Schernthaner G, Schober E and Schernthaner GH: Endothelial progenitor cells are related to glycemic control in children with type 1 diabetes over time. Diabetes Care 36: 1647-1653, 2013.

40. António N, Fernandes R, Soares A, Soares F, Lopes A, Carvalheiro T, Paiva A, Pêgo GM, Providência LA, Gonçalves L and Ribeiro CF: Reduced levels of circulating endothelial progenitor cells in acute myocardial infarction patients with diabetes or pre-diabetes: Accompanying the glycemic continuum. Cardiovasc Diabetol 13: 101, 2014

41. Ingram DA, Lien IZ, Mead LE, Estes M, Prater DN, Derr-Yellin E, DiMeglio LA and Haneline LS: In vitro hyperglycemia or a diabetic intrauterine environment reduces neonatal endothelial colony-forming cell numbers and function. Diabetes 57: 724-731, 2008.

42. Tsukada S, Masuda H, Jung SY, Yun J, Kang S, Kim DY, Park JH, Ji ST, Kwon SM and Asahara T: Impaired development and dysfunction of endothelial progenitor cells in type 2 diabetic mice. Diabetes Metab 43: 154-162, 2017.

43. Fadini GP, Sartore S, Schiavon M, Albiero M, Baesso I, Cabrelle A, Agostini C and Avogaro A: Diabetes impairs progenitor cell mobilisation after hindlimb ischaemia-reperfusion injury in rats. Diabetologia 49: 3075-3084, 2006.

44. Kryczek I, Lange A, Mottram P, Alvarez X, Cheng P, Hogan M, Moons L, Wei S, Zou L, Machelon V, et al: CXCL12 and vascular endothelial growth factor synergistically induce neoangiogenesis in human ovarian cancers. Cancer Res 65: 465-472, 2005.
45. Uruno A, Yagishita Y and Yamamoto M: The Keap1-Nrf2 system and diabetes mellitus. Arch Biochem Biophys 566: 76-84, 2015.

46. Florczyk U, Jazwa A, Maleszewska M, Mendel M, Szade K, Kozakowska M, Grochot-Przeczek A, Viscardi M, Czauderna S, Bukowska-Strakova $\mathrm{K}$, et al: Nrf2 regulates angiogenesis: Effect on endothelial cells, bone marrow-derived proangiogenic cells and hind limb ischemia. Antioxid Redox Signal 20: 1693-1708, 2014.

47. Gremmels H, de Jong OG, Hazenbrink DH, Fledderus JO and Verhaar MC: The transcription factor Nrf2 protects angiogenic capacity of endothelial colony-forming cells in high-oxygen radical stress conditions. Stem Cells Int 2017: 4680612, 2017.

48. Chiu SC, Chao CY, Chiang EI, Syu JN, Rodriguez RL and Tang FY: N-3 polyunsaturated fatty acids alleviate high glucose-mediated dysfunction of endothelial progenitor cells and prevent ischemic injuries both in vitro and in vivo. J Nutr Biochem 42: 172-181, 2017.

49. Vaamonde-Garcia C, Courties A, Pigenet A, Laiguillon MC, Sautet A, Houard X, Kerdine-Römer S, Meijide R, Berenbaum F, and Sellam J: The nuclear factor-erythroid 2-related factor/heme oxygenase-1 axis is critical for the inflammatory features of type 2 diabetes-associated osteoarthritis. J Biol Chem 292: $14505-14515,2017$.

50. Tullet JMA, Green JW, Au C, Benedetto A, Thompson MA, Clark E, Gilliat AF, Young A, Schmeisser K and Gems D: The SKN-1/Nrf2 transcription factor can protect against oxidative stress and increase lifespan in C. Elegans by distinct mechanisms. Aging Cell 16: 1191-1194, 2017.

51. Corenblum MJ, Ray S, Remley QW, Long M, Harder B, Zhang DD, Barnes CA and Madhavan L: Reduced Nrf 2 expression mediates the decline in neural stem cell function during a critical middle-age period. Aging Cell 15: 725-736, 2016.

52. Gao S, Duan X, Wang X, Dong D, Liu D, Li X, Sun G and Li B: Curcumin attenuates arsenic-induced hepatic injuries and oxidative stress in experimental mice through activation of Nrf2 pathway, promotion of arsenic methylation and urinary excretion. Food Chem Toxicol 59: 739-747, 2013.

This work is licensed under a Creative Commons Attribution-NonCommercial-NoDerivatives 4.0 International (CC BY-NC-ND 4.0) License. 